\title{
A dimensão esquecida da política habitacional: reflexões a partir do caso da Área Metropolitana de Curitiba (PR)
}

The forgotten dimension of the housing policy: reflections on the case of the metropolitan area of Curitiba (State of Paraná)

Paulo Nascimento Neto [I]

\begin{abstract}
Resumo
Os últimos quinze anos caracterizaram-se pela revalorização da política habitacional no cenário nacional, com a construção de um arcabouço institucional e a produção massiva de unidades. Presenciou-se o desenvolvimento de uma série de pesquisas vinculadas, sobretudo, ao Programa Minha Casa Minha Vida. Nesse contexto, este artigo se insere em uma discussão mais profunda e latente, tendo por objetivo investigar as dinâmicas envoltas na sobreposição da problemática habitacional sobre os espaços metropolitanos, espaços de especial interesse, já que concentram mais de metade do déficit e cerca de $80 \%$ dos assentamentos subnormais do País. Por meio do estudo da Área Metropolitana de Curitiba, busca-se refletir sobre a "dimensão esquecida", sem a qual os esforços empreendidos arriscam não atingir os efeitos esperados.
\end{abstract}

Palavras-chave: política habitacional; região metropolitana; habitação social; políticas públicas; Curitiba.

\begin{abstract}
In Brazil, the housing policy regained importance over the last fifteen years, with the construction of an institutional framework and the massive production of affordable houses. Several studies were developed, mainly related to the housing program Minha Casa Minha Vida. In this scenario, this article is part of a deeper and latent discussion: it aims to investigate the dynamics involved in the overlap between housing issues and metropolitan areas, spaces of special interest, as they concentrate more than half of the housing deficit and about $80 \%$ of informal settlements in Brazil. Through a study of the Metropolitan Area of Curitiba, we seek to discuss the "forgotten dimension", without which the undertaken efforts may not produce the expected effects.
\end{abstract}

Keywords: housing policy; metropolitan region; social housing; public policies; Curitiba. 


\section{Introdução}

Os debates e pesquisas envolvendo a política habitacional, de um lado, e a escala metropolitana, de outro, ocuparam uma centralidade de destaque ao longo da última década. Os avanços da política habitacional ao longo da década de 2000 são incontestáveis, bem como os contrassensos gerados por um programa habitacional que se desvinculou da sua política geradora. Ao delegar, ao mercado, o protagonismo da política habitacional, reproduziu-se um padrão de segregação socioterritorial e de precariedade urbano-ambiental que guarda similaridades com o modelo BNH.

Uma série de estudos ao longo da última década evidenciou essas limitações, sendo recorrente a deficitária compatibilização com a política fundiária e a inexistência de integração entre as políticas municipais nos espaços metropolitanos (Cardoso, Aragão, Jaenisch, 2017; Shimbo, 2012; Royer, 2009; Cardoso, 2013; Denaldi, Klink, Souza, 2010; Nascimento Neto, Moreira, 2017; Maricato, 2014). Essa discussão revela sua central importância ao se observar que mais de metade do déficit habitacional (FJP, 2013) e cerca de $80 \%$ dos aglomerados subnormais do País (IBGE, 2010a) se concentram nas áreas metropolitanas.

Concomitantemente, as novas perspectivas advindas da aprovação do Estatuto da Metrópole (lei federal n. 13.089/2015) ainda não encontraram aderência na agenda políti$\mathrm{ca}$, insistentemente localista. 0 planejamento integrado e a atuação coordenada interfederativa, até então "órfãos" do interesse político (Ribeiro, 2004) e do próprio pacto federativo brasileiro (Klink, 2013), ao mesmo tempo que se tornam objeto de novos debates (Marguti, Costa, Favarão, 2018), se tornam substrato de questionamentos sobre a sua capacidade de reescalonar políticas urbanas em direção aos espaços efetivos de produção contemporânea do espaço (Hoshino, Moura, 2019).

Em um contexto de assimetrias entre os municípios metropolitanos, concentração da dinamicidade econômica e segregação socioespacial, observa-se com frequência a "exportação" do déficit habitacional dos municípios-polo (com elevado preço da terra) para os municípios mais pobres, em que o preço da terra é inferior e a capacidade de controle do uso e ocupação do solo é reduzida, criando as condições ideais para uma urbanização periférica caracterizada pela ilegalidade e carência de infraestrutura (Fix, Pereira, 2013; Gonçalves, 2011; Royer, 2013; Maricato, 2011; Bonduki, 2013).

Os municípios com menor arrecadação e com taxas de crescimento significativas, então, veem-se obrigados a realizar pesados investimentos não somente nas áreas de habitação e infraestrutura, mas também em mobilidade urbana, transporte coletivo, saneamento, gestão de resíduos sólidos e equipamentos sociais. A promoção habitacional também possui estreita relação com o uso e a ocupação do solo, que por sua vez estão diretamente relacionados ao direcionamento do crescimento urbano e à preservação ambiental de mananciais de abastecimento e áreas ambientalmente sensíveis.

Costa et al. (2010), contribuindo com a discussão, alertam para o risco de a atuação fragmentada no campo habitacional tornar-se também concorrente, delineamento um cenário de disputa na captação de recursos provenientes de outras esferas governamentais e mesmo da iniciativa privada. Considerando o protagonismo do mercado no modelo 
altamente financeirizado em que a política habitacional brasileira se insere, os riscos ampliam-se diante de um cenário de flexibilização do regramento de uso e ocupação do solo e enfraquecimento dos princípios do direito à moradia digna, em direção à atuação articulada entre agentes políticos e mercado da construção civil, em um movimento no qual o número de unidades construídas em um município exprime o "sucesso" da política local, de forma alheia ao contexto metropolitano.

De fato, a interdependência entre os municípios e entre suas políticas setoriais é manifesta, demandando arranjos intergovernamentais de coordenação e cooperação federativa, de forma a combater a fragmentação das políticas e viabilizar a atuação na escala metropolitana. Contudo, de que forma é possível se pensar na integração de políticas públicas de habitação em regiões metropolitanas?

Ainda que o Sistema Nacional de Habitação seja descentralizado e delegue aos governos subnacionais o papel executor, o governo federal desempenha papel fundamental, de modo que as prioridades dos governos estaduais e municipais são condicionadas pelas políticas federais (Arretche et al., 2012). A despeito da importância dessa constatação, observa-se que os principais instrumentos da política habitacional no Brasil desconsideram a integração metropolitana dentro de seu escopo: a Política Nacional de Habitação (PNH) traz apenas recomendações pontuais de estímulo à criação e ao fortalecimento das estruturas institucionais regionais e metropolitanas; o Plano Nacional de Habitação (PlanHab) circunscreve as estratégias de enfrentamento da problemática habitacional dentro da escala local; e o Programa Minha Casa Minha Vida
(PMCMV) adota o município como única unidade de planejamento.

Complementarmente, ainda que o PlanHab (MCidades, 2009) reconheça a ausência de instâncias regionais de articulação da ação de estados e municípios nas regiões metropolitanas, apenas recomenda o dimensionamento integrado do estoque de terras e déficit habitacional se constatada a insuficiência de cada município em atender a suas necessidades isoladamente. Estudos recentes evidenciam essa "municipalização" da política habitacional, que se exime ou relega ao segundo plano a dimensão metropolitana (Bonduki, 2013; Royer, 2013; Souza, 2009; Costa et al., 2010; Costa, Mendonça, 2010), reproduzindo o padrão de urbanização excludente e de periferização da pobreza característico dos países latino-americanos (Cardoso, Araújo, Aragão, 2011).

A despeito da existência de estudos evidenciando as limitações das políticas públicas habitacionais, nos diferentes níveis federativos, em fomentar ou estabelecer a integração entre os municípios metropolitanos, a produção científica brasileira carece de maiores pesquisas sobre os fatores geradores de obstáculos e constrangimentos à articulação intermunicipal no campo da moradia (Nascimento Neto, Moreira, 2014). Arretche et al. (2012, p. 132) corroboram o exposto afirmando que: "pouco se sabe sobre como cooperam os municípios brasileiros para a oferta de serviços habitacionais" e "pouco foi examinado acerca dessas relações e sua importância para a oferta habitacional".

Diante do exposto, tem-se este artigo por objetivo contribuir com o campo a partir da investigação das relações entre dinâmica metropolitana e problemática habitacional, 
subsidiando discussões mais amplas sobre a integração das políticas de habitação em áreas metropolitanas a partir do estudo de caso da área metropolitana de Curitiba (PR). Para tanto, ele se organiza em três seções: a primeira, relacionada à discussão dos procedimentos metodológicos; a segunda, relacionada à reconstrução histórica do caso estudado; e a terceira, que busca discutir casos concretos tipificantes da realidade identificada.

\section{Procedimento metodológicos e recorte de análise}

Em consonância com o objetivo delineado, adotou-se como estratégia de pesquisa o estudo de caso qualitativo (Godoi, 2006) e instrumental (Stake, 2005), visando a investigar, de forma profunda, uma unidade de análise específica, compreendendo sua idiossincrasia e sua complexidade, mas também contribuindo com um entendimento mais amplo - no caso deste artigo: a compreensão da questão habitacional no contexto metropolitano.

O estudo de caso foi desenvolvido na Região Metropolitana de Curitiba (PR), caso representativo da questão no contexto brasileiro. Essa decisão encontra fundamentos em Stake (ibid.) e Yin (2005), para os quais a seleção do caso estudado não deve se balizar por amostras estatísticas, tendo em vista que o que se busca é uma generalização analítica, e não estatística.

Assim, a escolha do estudo de caso deu-se de forma não probabilística e intencional, considerando primordialmente três aspectos: (1) seu enquadramento, tipificante no fenômeno metropolitano brasileiro; ${ }^{1}$ (2) sua participação no conjunto das nove regiões metropolitanas criadas na década de 1970, na qual a dinâmica atual expressa o palimpsesto de contradições e progressos que caracterizam a "urbanização do capitalismo periférico" (Maricato, 2011); e, por fim, (3) a trajetória do órgão de política habitacional no município-polo (Cohab-CT, em Curitiba) que se destacou nas décadas de 1970 e 1980 pela relação concertada com o órgão metropolitano (Comec), mantendo, mesmo após a municipalização de sua atuação pós-1988, alguns serviços específicos em parceria com municípios metropolitanos.

Dentro do caso da RM de Curitiba, optou-se, ainda, por restringir o recorte de estudo apenas aos municípios com um nível representativo de integração à dinâmica metropolitana. Essa decisão metodológica parte de dois entendimentos: a dissociação existente entre as regiões institucionalizadas e os espaços efetivamente metropolitanos (Moura, Firkowski, 2014; Korin, Carmo, 2013); e a especificidade da espacialização das demandas urbanas, que se distribuem de forma distinta no território, tendo em vista que "nem todo problema metropolitano é um problema de todo município metropolitano" (Rolnik, Somekh, 2004, p. 122).

Desse modo, adotou-se como amostra de pesquisa os 14 municípios que integram o núcleo urbano central (NUC), ${ }^{2}$ recorte espacial que efetivamente representa a aglomeração metropolitana (Comec, 2006), concentrando 97,73\% da população urbana da Região Metropolitana, 2,99 milhões de habitantes (IBGE, 2010b) e grau de urbanização médio de 95\%. Com vistas a facilitar a menção ao objeto de pesquisa e diferenciá-lo da Região Metropolitana propriamente dita, adota-se a expressão Área Metropolitana (AM) de Curitiba para se referir à amostra de pesquisa deste trabalho. 
Figura 1 - Localização da área metropolitana de Curitiba

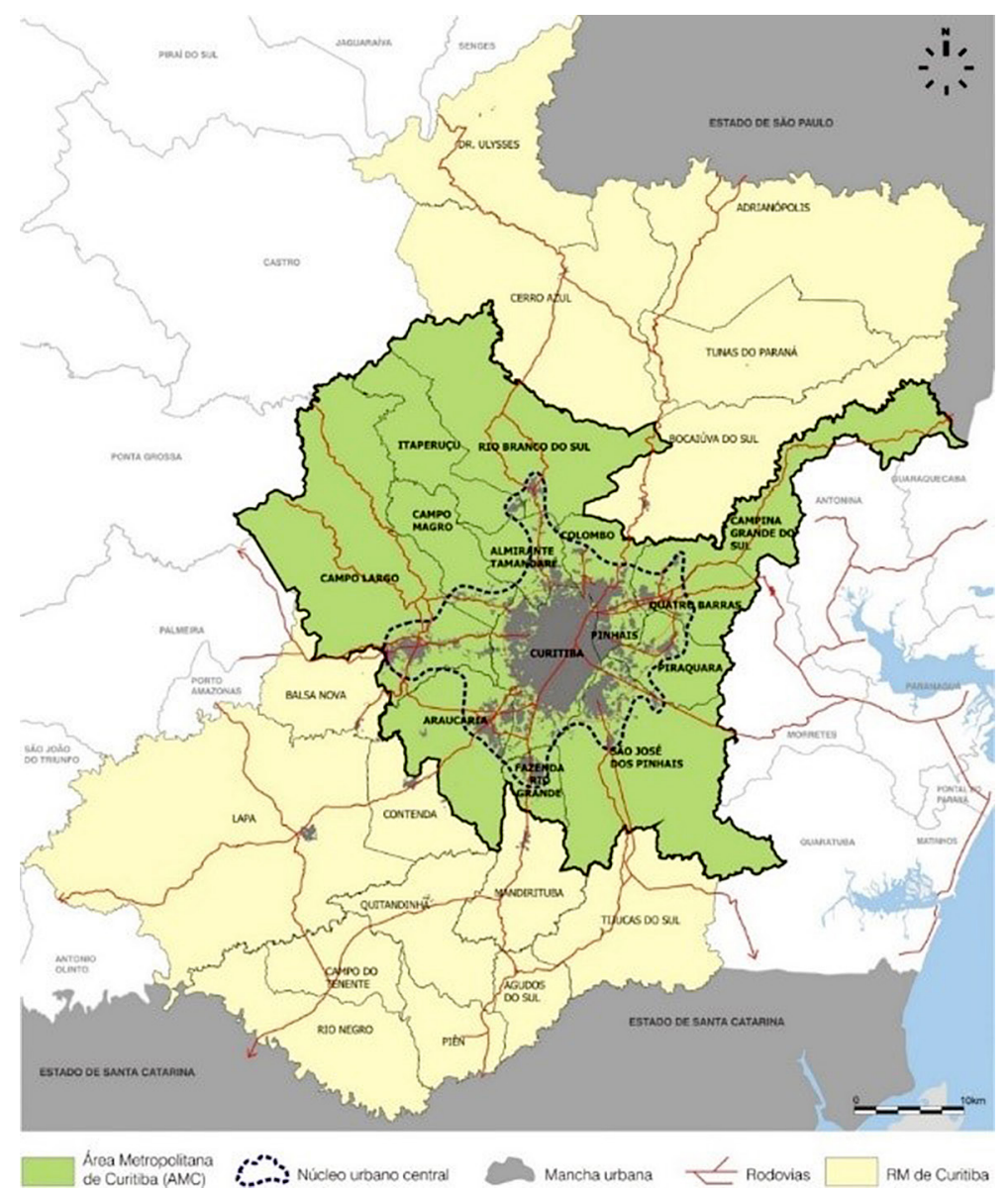

Fonte: autor, sobre base cartográfica de Comec

\section{Análise e coleta de dados}

Foram adotadas, como técnicas de coletas de dados, a pesquisa documental e a realização de entrevistas semiestruturadas (Yin, 2005; Godoi, 2006). Para a seleção dos entrevistados, trabalhou-se com o conceito de amostragem teórica (Glaser, Strauss, 2006), no qual os respondentes são selecionados conforme critérios específicos e segundo seu nível de significância para o caso estudado, de forma a auxiliar o pesquisador a testar suas proposições teóricas. Buscou-se captar a percepção acerca dos obstáculos à cooperação intermunicipal no campo habitacional, segundo o ponto de vista dos gestores públicos relacionados tanto com o planejamento quanto com a consecução da referida política (em nível municipal, estadual e metropolitano). ${ }^{3}$ Complementarmente, buscou-se entrevistar outros atores relevantes, incluindo consultores técnicos e o agente financeiro. 
Em relação aos municípios, foram selecionados para a realização das entrevistas aqueles com grau alto ou muito alto de integração à dinâmica metropolitana, conforme classificação desenvolvida por Ribeiro (2009). De forma complementar, optou-se, também, pela realização da entrevista com um município com grau médio de integração (Campo Largo), de forma a obter um ponto de vista diverso dos demais. Para a escolha dos entre- vistados, o pesquisador desenvolveu levantamento prévio nos órgãos, considerando três critérios: posição de direção ou gerência no órgão (preferencialmente não em cargo de comissão); trajetória profissional na área; e participação direta na elaboração do plano ou na consecução da política habitacional.

Com base nos critérios expostos, foram realizadas 18 entrevistas (Quadro 1), a partir das quais se coletou material consistente para

Quadro 1 - Relação de respondentes - entrevista semiestruturada

\begin{tabular}{|c|c|c|c|}
\hline \multicolumn{2}{|r|}{ Nível } & \multicolumn{2}{|r|}{ Órgão de atuação do entrevistado ${ }^{4}$} \\
\hline \multicolumn{2}{|c|}{ Federal } & (entrev. 1) & Ministério das Cidades \\
\hline \multirow{4}{*}{\multicolumn{2}{|c|}{ Estadual }} & (entrev. 2) & Companhia de Habitação do Paraná (Cohapar) \\
\hline & & (entrev. 3) & Secretaria de Desenvolvimento Urbano do Paraná (Sedu) \\
\hline & & (entrev. 4) & Paraná cidade \\
\hline & & (entrev. 5) & Secretaria Estadual de Planej. e Coordenação Geral (SEPL) \\
\hline \multirow{2}{*}{\multicolumn{2}{|c|}{ Metropolitano(') }} & (entrev. 6) & Coordenação da Região Metropolitana de Curitiba (Comec) \\
\hline & & (entrev. 7) & Coordenação da Região Metropolitana de Curitiba (Comec) \\
\hline \multirow{9}{*}{ 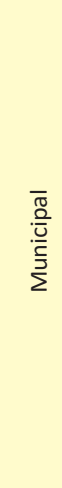 } & Almirante Tamandaré & (entrev. 8) & Departamento de Habitação \\
\hline & Campo Largo & (entrev.9) & Secretaria Municipal de Desenvolvimento Urbano \\
\hline & Colombo & (entrev. 10) & Secretaria Municipal de Desenvolvimento Urbano e Habitação \\
\hline & \multirow{2}{*}{ Curitiba } & (entrev. 11) & Companhia de Habitação Popular de Curitiba (Cohab-CT) \\
\hline & & (entrev. 12) & Instituto de Pesquisa e Planejamento Urbano (Ippuc) \\
\hline & Fazenda Rio Grande & (entrev. 13) & Secretaria de Ação Social, Trabalho e Habitação \\
\hline & Pinhais & (entrev. 14) & Departamento de Planejamento Urbano \\
\hline & Piraquara & (entrev. 15) & Secretaria de Meio Ambiente e Urbanismo \\
\hline & São José dos Pinhais & (entrev. 16) & Secretaria Municipal de Habitação \\
\hline \multirow{2}{*}{\multicolumn{2}{|c|}{ Demais atores sociais relevantes }} & (entrev. 17) & Caixa Econômica Federal - Gerência Reg. de Construção Civil \\
\hline & & (entrev. 18) & Empresa de consultoria em Planejamento Urbano ${ }^{(2)}$ \\
\hline
\end{tabular}

Notas:

(') para a Comec foram realizadas duas entrevistas, tendo em vista a complementaridade de funções e a indicação do segundo entrevistado pelo primeiro, devido a sua experiência e conhecimento

$\left({ }^{2}\right)$ A empresa foi selecionada tendo em vista que a mesma prestou consultoria técnica para a elaboração do PLHIS de cinco municípios da AMC ( $36 \%$ do total). 
investigar a temática de interesse desta pesquisa. As entrevistas foram gravadas e posteriormente transcritas. Utilizou-se a Análise de Conteúdo (Bardin, 1994), adotando-se o software Atlas.ti $6.0^{\circledR}$ como ferramenta de apoio.

A pesquisa documental, segunda técnica de pesquisa adotada, procura identificar e analisar os documentos norteadores da política habitacional que possuem influência sobre o recorte territorial de estudo. Assim, partiu-se, inicialmente, dos planos elaborados nos diferentes níveis governamentais relacionados ao caso estudado (Quadro 2). A partir destes planos, acredita-se que seja possível obter uma saturação de dados, adquirindo informações para uma análise consistente (Godoi, 2006).

Cabe ressaltar que a utilidade desses documentos não se baseia em sua ausência de vieses (Yin, 2005), devendo-se interpretá-los criteriosamente. Entretanto, como os documentos básicos pesquisados envolvem instrumentos oficiais de planejamento (e que, portanto, balizam a utilização dos recursos públicos), eles permitem a compreensão das diretrizes das políticas habitacionais engendradas em cada nível governamental, ao menos em seu aspecto formal.

A partir da triangulação dos dados, busca-se discutir o tema deste artigo. Essa triangulação ${ }^{5}$ é defendida por diversos autores como fundamental no desenvolvimento de estudos de caso, garantindo que múltiplas fontes de evidência forneçam consistência aos resultados obtidos (Yin, 2005; Stake, 2005; Godoi, 2006).

\section{A questão habitacional na área metropolitana de Curitiba: uma leitura longitudinal}

De forma a contextualizar a discussão, nesta seção se busca, de forma sintética e compatível com a extensão de um artigo científico, explorar a trajetória histórica recente das políticas de gestão metropolitana e de habitação

Quadro 2 - Planos analisados segundo nível governamental

\begin{tabular}{|l|l|l|c|}
\hline \multicolumn{1}{|c|}{ Nível } & \multicolumn{1}{|c|}{ Instrumento de planejamento } & \multicolumn{1}{c|}{ Órgão responsável } & Quant. \\
\hline Municipal & $\begin{array}{l}\text { Plano Diretor Municipal } \\
\text { Plano Local de Habitação de Interesse Social }\end{array}$ & $\begin{array}{l}\text { Pref. Municipal } \\
\text { Pref. Municipal }\end{array}$ & $\begin{array}{l}13^{*} \\
07^{*}\end{array}$ \\
\hline Metropolitano & Plano de Desenvolvimento Integrado & Comec & 1 \\
\hline Estadual & Plano de Habitação Social & Cohapar & 1 \\
\hline Nacional & Plano Nacional de Habitação & Ministério das Cidades & 1 \\
\hline & Política Nacional de Habitação & Ministério das Cidades & 24 \\
\hline
\end{tabular}

Nota: * Para discriminação dos municípios segundo plano e ano de elaboração, consultar Quadro 3. 
na área metropolitana de Curitiba, explicitando de que forma as políticas urbanas se desenvolveram ao longo das duas últimas décadas, recorte suficiente para se compreender a temática desde seu momento recente.

Cabe destacar que as análises encontradas na bibliografia focam, via de regra, em apenas um dos temas e, majoritariamente, limitam-se a analisar apenas o município-polo. Diante desse contexto, buscou-se avançar em uma reconstrução histórica efetivamente metropolitana. A partir dessa ponderação, discutem-se, no item seguinte, casos concretos do palimpsesto resultante da sobreposição das demandas habitacionais sobre as dinâmicas espaciais dos espaços metropolitanos.

\section{A década de 2000 e a emergência das políticas urbanas e habitacionais}

Em âmbito nacional, a década de 2000 caracteriza-se por significativos avanços no âmbito das políticas urbanas, com destaque para a aprovação do Estatuto da Cidade, a estruturação do Ministério das Cidades e a definição de uma estratégia consistente de enfrentamento da questão habitacional (Política, Plano e Fundo Nacional de Habitação). A partir das novas disposições legais, os municípios foram compelidos a elaborar ou a rever seus planos diretores, adequando-os ao novo diploma legal. Particularmente no estado do Paraná, esse movimento foi complementado pela lei estadual 15.229/006, que estabeleceu normativa complementar e condicionou o acesso a recursos estaduais à existência de Plano Diretor Municipal vigente. A exigência legal foi acompanhada de um programa de apoio aos municípios, coordenada pelo Paraná Cidade, órgão vinculado ao Estado, com financiamento e acompanhamento técnico para elaboração dos planos.

Diante desse contexto, observam-se, neste período, a revisão do Plano Diretor de Curitiba e a elaboração do Plano Diretor Municipal em todos os demais municípios da AMC (com exceção de Itaperuçu). Na esteira desse processo, o final da década de 2000 é marcado pela elaboração dos Planos Locais de Habitação de Interesse Social, elaborados em consonância com as orientações nacionais, com o objetivo de equalizar as demandas habitacionais em curto, médio e longo prazo.

Esses dois instrumentos de planejamento (Planos Diretores e de Habitação) constituem os elementos (ao menos em tese) norteadores do desenvolvimento urbano e da política habitacional nos municípios metropolitanos. A seguir são apresentados os respectivos anos de elaboração, evidenciando a dinâmica descrita acima.

Em nível metropolitano, a década de 2000 também é marcada pela formulação do Plano de Desenvolvimento Integrado (PDI), no qual foram elaboradas estratégias de intervenção e controle do uso do solo, com forte viés de participação popular, ${ }^{6}$ visando a obter "consensos coletivos para a elaboração de projetos regionais que retirassem o caráter exclusivamente normativo que vinha ocorrendo no planejamento metropolitano" (Schussel, 2006, p. 202).

Embora esse PDI tenha sido parcialmente concluído em 2002, ele não foi implementado devido à mudança de governo em 2003, com alinhamento político contrário ao anterior. Como resultado, em 2006, tem-se a elaboração de um novo Plano Metropolitano, que se fundamentou no estreito vínculo entre 
Quadro 3 - Ano de elaboração ou revisão de PDs e PLHIS por município da AMC

\begin{tabular}{|l|c|c|}
\hline \multirow{2}{*}{ Município } & \multicolumn{2}{|c|}{ Ano de elaboração } \\
\cline { 2 - 3 } & Plano Diretor Municipal & PLHIS \\
\hline Almirante Tamandaré & 2006 & [em elaboração] \\
Araucária & 2007 & 2011 \\
Campina Grande do Sul & $2015(2005)^{1}$ & 2010 \\
Campo Largo & 2005 & 2009 \\
Campo Magro & $2012(2005)^{2}$ & [em elaboração] \\
Colombo & 2004 & [em elaboração] \\
Curitiba & 2015 & 2008 \\
Fazenda Rio Grande & 2006 & 2010 \\
Itaperuçu & {$[$ em elaboração] } & [não possui] \\
Pinhais & 2011 & 2010 \\
Piraquara & 2006 & [em elaboração] \\
Quatro Barras & 2006 & 2011 \\
Rio Branco do Sul & 2011 & [em elaboração] \\
São José dos Pinhais & 2015 & 2010 \\
\hline
\end{tabular}

Fonte: levantamento do autor - situação em fevereiro de 2015.

Notas: ${ }^{1} \mathrm{O}$ município ainda está elaborando a revisão de seu Plano Diretor

${ }^{2}$ O Plano Diretor foi elaborado em 2005, mas a aprovação das leis ocorreu apenas em 2012.

a gestão dos recursos hídricos e as políticas gerais de desenvolvimento metropolitano, visando a definir marcos estratégicos balizadores das políticas setoriais (Comec, 2006). Para Gorsdorf (2009) e Santos Jr. (2009), esse plano não foi apropriado pela sociedade civil e pela ação pública, restringindo-se à equipe interna designada para sua elaboração.

Como observado por Kornin e Carmo (2013), ao longo da década de 2000, a Comec passou por um gradativo enfraquecimento, restringindo sua atuação ao controle do ordenamento territorial (aprovação de loteamentos), à elaboração de projetos de infraestrutura e mobilidade urbana e ao (conturbado) processo de gestão da rede integrada de transporte público.
Em relação à política habitacional em escala metropolitana, o final da década de 2000 é marcado pela consolidação da Cohapar como agente central de consecução da política nos municípios metropolitanos. Nesse contexto, foi de fundamental importância a disponibilização de recursos federais no âmbito do Programa de Aceleração do Crescimento (PAC). Até então as fontes de recurso eram escassas e, como consequência, sequer se promoviam ações de regularização fundiária (Entrevistado 2; Entrevistado 11).

Nas palavras de Cohapar (2012, p. 71), "pela primeira vez foram implantados empreendimentos integrando os serviços de infraestrutura urbana como redes de água, esgoto, energia, contenção de enchentes, 
equipamentos sociais, parques e habitação". Os dados da Cohapar (2015) reiteram o exposto, verificando-se a contratação de projetos de regularização fundiária e produção habitacional em Piraquara, Pinhais, Colombo e Campo Magro, todos executados com recursos do PAC e com contrapartida do governo do Estado.

Em relação à Cohab-CT, órgão de política habitacional local de Curitiba, percebe-se o deslocamento de seu foco de atuação exclusivamente para o município de Curitiba, com projetos pontuais em alguns municípios do entorno (Gráfico 1). Aqui, cabe destacar que sua atuação originária, na década de 1970, envolvia uma atuação de corte metropolitano.

Particularmente sobre essa alteração de posicionamento, deve-se ressaltar a modificação realizada no Fundo Municipal de
Habitação em 2008, a partir de quando foi vetada a sua utilização em projetos situados nos demais municípios metropolitanos, à exceção dos casos em que se tenha por objetivo "fazer frente às regularizações fundiárias provenientes do município de Curitiba" (§ 2으 do artigo 8oㅡ da lei n. 12816/2008).

Ainda sobre o município de Curitiba, é digna de menção a série de modificações na legislação de uso e ocupação do solo vinculada à questão habitacional. A figura da SEHIS é reformulada na lei n. 9800/2000 e passa a envolver "áreas onde há interesse público em ordenar a ocupação por meio de urbanização e regularização fundiária, em implantar ou complementar programas habitacionais de interesse social". Posteriormente, por meio da lei n. 12.450/2007 foram instituídas as zeis Vila Formosa e Vila Parolin. ${ }^{7}$

Gráfico 1 - Unidades produzidas pela Cohab-CT entre 2000 e 2009 por município

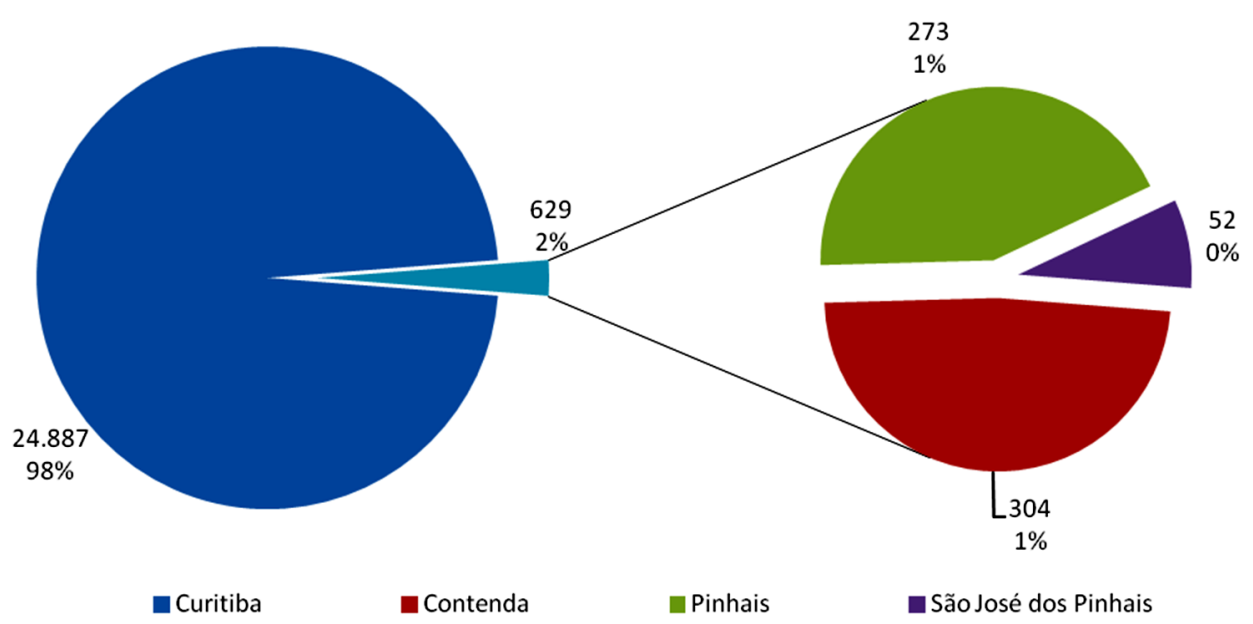

Fonte: autor, com base em dados da Cohab-CT. 
Ao se visualizar a localização das SEHIS e zeis existentes em Curitiba e cruzá-la com a localização das ocupações irregulares no município, percebe-se que, apesar de estas estarem distribuídas ao longo de todo o território, os SEHIS restringem-se a áreas periféricas na porção sul do município (Figura 2), cristalizando a concepção de periferização da população de baixa ren$\mathrm{da}$, em áreas com baixa acessibilidade a transporte, equipamentos públicos e serviços. ${ }^{8}$

Figura 2 - Ocupações irregulares, SEHIS e zeis em Curitiba-PR

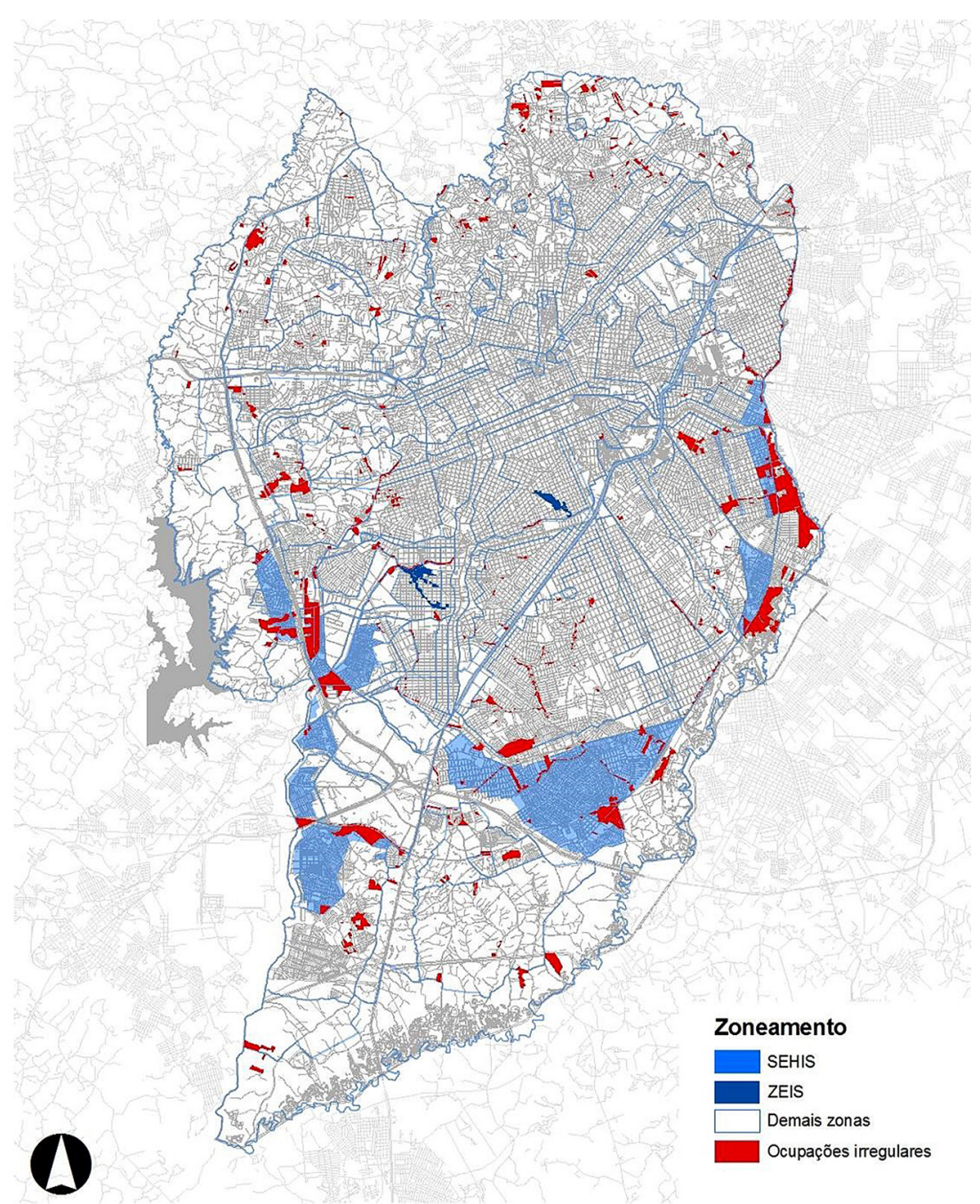

Fonte: autor, com base em dados da Prefeitura Municipal de Curi- 
Apesar dos avanços na legislação urbanística e da retomada de programas habitacionais em Curitiba e região metropolitana, observa-se o incremento do déficit habitacional entre 2000 e 2010, com destaque para Campo Magro (+298\%), Piraquara (+175\%), Colombo (+92\%), Araucária (+91\%) e Fazenda Rio Grande $(+89,71 \%)$. Ainda com base nos dados apresentados na Tabela 1, observa-se que Curitiba $(60,11 \%)$, São José dos Pinhais (8,28\%), Pinhais (4,12\%) e Araucária (4,05\%) destacam-se dentro da participação relativa no déficit metropolitano. Em ambas as análises, verifica-se a presença de municípios significativamente atingidos por áreas de manancial de abastecimento hídrico, denotando um problema de complexa resolução.

Em relação aos assentamentos precários, é necessário salientar que, para a escala metropolitana, não há um sistema de informações que permita compilar séries históricas, dificultando a comparação em relação aos números apresentados para a década de 1990. Em termos gerais, o levantamento de Silva (2012) aponta que os vetores de expansão dos assentamentos precários nesse período se direcionam para a região norte do aglomerado metropolitano (Curitiba, Campo Largo, Campo Magro e Almirante Tamandaré) e região sudeste (São José dos Pinhais). ${ }^{9}$

Tabela 1 - Déficit habitacional por município (2000-2010) da AMC

\begin{tabular}{|c|c|c|c|c|c|}
\hline \multirow{2}{*}{ Município } & \multicolumn{2}{|c|}{2000} & \multicolumn{2}{|c|}{2010} & \multirow{2}{*}{$\begin{array}{c}\text { Variação } \\
2000-2010 \text { (\%) }\end{array}$} \\
\hline & Abs. & $\%$ & Abs. & $\%$ & \\
\hline Almirante Tamandaré & 2.193 & 4,37 & 2.727 & 3,33 & 24,34 \\
\hline Araucária & 1.734 & 3,46 & 3.314 & 4,05 & 91,11 \\
\hline Campina Grande do Sul & 779 & 1,55 & 939 & 1,15 & 20,59 \\
\hline Campo Largo & 1.470 & 2,93 & 2.326 & 2,84 & 58,21 \\
\hline Campo Magro & 207 & 0,41 & 825 & 1,01 & 298,34 \\
\hline Colombo & 2.970 & 5,92 & 5.717 & 6,99 & 92,50 \\
\hline Curitiba & 31.240 & 62,32 & 49.164 & 60,11 & 57,38 \\
\hline Fazenda Rio Grande & 1.189 & 2,37 & 2.256 & 2,76 & 89,71 \\
\hline Itaperuçu & 496 & 0,99 & 512 & 0,63 & 3,18 \\
\hline Pinhais & 2.026 & 4,04 & 3.366 & 4,12 & 66,12 \\
\hline Piraquara & 1.021 & 2,04 & 2.810 & 3,44 & 175,25 \\
\hline Quatro Barras & 325 & 0,65 & 481 & 0,59 & 48,12 \\
\hline Rio Branco do Sul & 844 & 1,68 & 574 & 0,70 & $-31,97$ \\
\hline São José dos Pinhais & 3.635 & 7,25 & 6.775 & 8,28 & 86,39 \\
\hline Total & 50.129 & 100,00 & 81.786 & 100,00 & 63,15 \\
\hline
\end{tabular}

Fonte: autor, com base em dados da FJP $(2000,2010)$. 
No que tange ao mercado imobiliário formal, essa década é caracterizada pela migração de excedentes de capital imobiliário vindos de circuitos produtivos de outros estados (predominantemente São Paulo), alocados no mercado local e beneficiados pela expansão do crédito imobiliário no País. Como resultado, observa-se a intensificação da produção imobiliária, com impacto sobre o valor do solo urbano bem como no movimento de extravasamento da classe média e alta em direção aos municípios lindeiros, pressionando a população de baixa renda para setores ainda mais distantes. A análise do valor de mercado dos terrenos em Curitiba evidencia essa dinâmica, sendo possível perceber significativa elevação dos preços dos terrenos em Curitiba justamente a partir de 2004.

Diante desse cenário, passa a ser recorrente no discurso dos gestores públicos a dificuldade em viabilizar programas habitacionais devido ao alto custo do solo urbano. Não somente em Curitiba - onde esse elemento é historicamente repetido nos planos municipais -, mas também nos demais municípios metropolitanos essa narrativa esteve presente ao longo de todas as entrevistas realizadas (Entrevistados 8 a 16).

Em 2009, o governo federal alavancou significativamente os investimentos para a produção habitacional por meio do Programa Minha Casa Minha Vida que, a despeito da

Figura 3 - Preço médio de terrenos para venda em Curitiba $\left(\mathrm{R} \$ \mathrm{~m}^{2}\right)$ -1996 a 2019 -

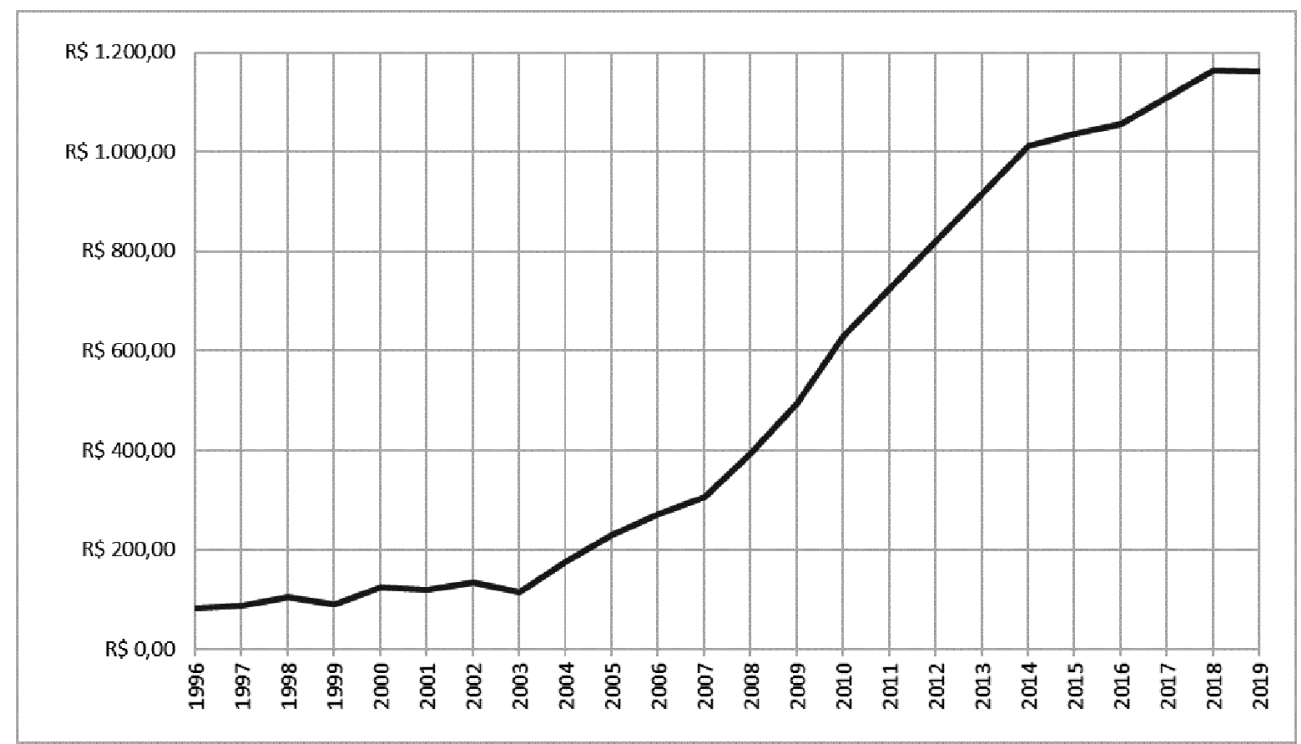

Fonte: autor, com base em Inpespar (apud Leitão, 2010) até 2010 e em dados de Inpespar (2019) para o período subsequente. 
inflexão positiva decorrente da injeção de recursos, gerou uma série de externalidades negativas. Os resultados são percebidos na década seguinte, na qual os empreendimentos são contratados, construídos e entregues.

\section{A questão habitacional como problema metropolitano: conjuntura atual (2010-2019)}

O panorama atual da política habitacional e de gestão metropolitana da AMC pode ser resumido, concomitantemente, a partir da continuidade e da ruptura da dinâmica relatada ao final do período anterior. Quatro pontos serão discutidos em maior profundidade: (1) os investimentos oriundos de recursos do PMCMV e os seus resultados; (2) o enfraquecimento do órgão metropolitano; (3) a macrocaracterização do espaço urbano metropolitano e a distribuição dos assentamentos precários; e (4) o processo recente de desmonte das estruturas de política urbana e habitacional.

Em relação à gestão metropolitana, o panorama atual é de intensificação do processo de desestruturação da Comec. Conforme relatado por técnicos do próprio órgão (Entrevistados 6 e 7), o órgão teve seu quadro técnico continuamente reduzido, limitando o escopo de atuação possível. Em complementação, os recursos disponíveis também são escassos. Diante desse contexto, conforme o Entrevistado 6, à exceção do controle do parcelamento do solo e das atividades vinculadas ao Conselho Gestor de Mananciais, tornou-se muito difícil intervir nas políticas urbanas, nas quais os municípios têm plena autonomia, e o órgão metropolitano não possui elementos de barganha (como, por exemplo, condicionamento de recursos).
Kornin e Carmo (2013) corroboram o exposto, identificando um processo de esvaziamento do espaço de planejamento e gestão metropolitana. Para os autores, ao longo da última década, a Comec limitou sua atuação à gestão das áreas de manancial e à gestão do transporte público e viário, com destaque para o segundo. Em relação ao primeiro, o Fundo de Preservação Ambiental (FPA) e o Sistema de Informações, Monitoramento e Fiscalização (Simf), parte integrante do sistema de gestão das áreas de manancial, sequer foram implementados. Somente o Conselho Gestor se manteve atuante, realizando as reuniões periódicas ao longo do tempo.

Como segundo elemento de destaque, a década de 2010 inicia-se para a política habitacional com forte impulso para a produção de unidades no âmbito do Programa Minha Casa Minha Vida. Com isso, os recursos, que antes eram direcionados ao FNHIS, foram realocados para o PMCMV, desvinculando-se do PLHIS, passando a responder majoritariamente ao interesse do mercado imobiliário, com grande concentração de investimentos da produção de novas unidades em detrimento dos projetos de regularização fundiária.

Na realidade, a iniciativa privada é o grande ator nesse processo juntamente com o governo federal, que é o detentor do recurso. (Entrevistado 17)

Com o Minha Casa Minha Vida, os recursos saíram do controle do Conselho de Habitação. Hoje as construtoras acessam diretamente os recursos, não existe um controle social. [...] Obviamente eles irão atuar naquilo que dê lucro a eles. A população com menor capacidade financeira fica desassistida e depende unicamente de programas feitos com recursos da OGU. E, mesmo 
para esses recursos, os municípios implementam os projetos em parceria com as construtoras. Como a prefeitura é a interessada direta, falta um órgão controlador, para fiscalizar a qualidade desses programas. (Entrevistado 2)

No caso do Minha Casa Minha Vida, ele não é um projeto de Cohab, ele é um projeto de construtora. Então a construtora que vai correr atrás de um terreno, que vai viabilizar nesse terreno a construção. $O$ que a prefeitura vai fazer? Além de uma redução de impostos federais, que está previsto na lei do MCMV, existem isenções fiscais do município de Curitiba, por exemplo, ITBI, IPTU durante o projeto, taxa de aprovação... isso tudo está previsto para que o cara ponha na conta. [...] Veja, o nosso papel hoje em habitação de interesse social, não é mais um papel de implantação. A gente pode, no máximo, discutindo com o Ippuc, criar perfis. Mas eu não posso mais... o próprio programa é muito engessado. Você não tem muita coisa para fazer. (Entrevistado 11)

Na esteira do PMCMV, o município de Curitiba editou o decreto n. 854/2009, ${ }^{10}$ estabelecendo parâmetros diferenciados para empreendimentos da iniciativa privada em parceria com a Cohab-CT. A despeito da existência de algumas regiões próximas do centro e dos eixos de transporte, nas quais se previa sua aplicação, constata-se que os empreendimentos enquadrados nesse decreto têm sido construídos em dois extremos do território municipal: no norte, próximo à divisa com Almirante Tamandaré; ou ao sul do município (Figura 4). Ambos os casos caracterizam-se por glebas distantes da malha, gerando empreendimentos em regiões com infraestrutura precária, sem equipamentos públicos e com densidade muito superior ao do seu entorno imediato.

A título de exemplo, pode-se mencionar o conjunto de empreendimentos Aroeiras e Imbuias, que totalizam mais de mil unidades e se localizam no extremo norte de Curitiba, em área distante da malha urbana na qual o município foi obrigado a arcar com pesados custos com infraestrutura e equipamentos urbanos. Como resultado desse processo, a ampliação da mais-valia capturada pelo empreendedor ocorreu simultaneamente à ampliação da oneração ao poder público, responsável por garantir condições mínimas de ocupação no lote.

Conforme relatou o Entrevistado 11, "você não tem nada em volta, uma farmácia, uma padaria, e não tem comércio no empreendimento. Então, tinha que ter escola, área para creche, para escola estadual....". Em entrevista à época para um jornal local, o próprio presidente da Cohab-CT reconheceu que a práxis atual divergia da situação minimamente desejada.

Até agora a prefeitura de Curitiba investiu $R \$ 9,5$ milhões em infraestrutura nas proximidades dos residenciais. "Para colocar essas famílias lá, precisamos criar toda uma infraestrutura com escola, posto de saúde, creche, escola estadual e linhas de ônibus", detalha o diretor-presidente da Cohab, Ubiraci Rodrigues. (Gazeta do Povo, 2014, sem página)

Ao se extrapolar a escala de análise para a Área Metropolitana de Curitiba (Tabela 2), a compilação da produção do MCMV entre 2009 e 2018 revela a concentração de oferta em Curitiba, com predominância de empreendimentos para a faixa 2 (75\% do total de unidades produzidas), apesar da clara concentração do déficit no segmento de menor renda (faixa 1). Em relação 
Figura 4-Empreendimentos MCMV Faixa 1, ocupações irregulares e renda média, Curitiba-PR

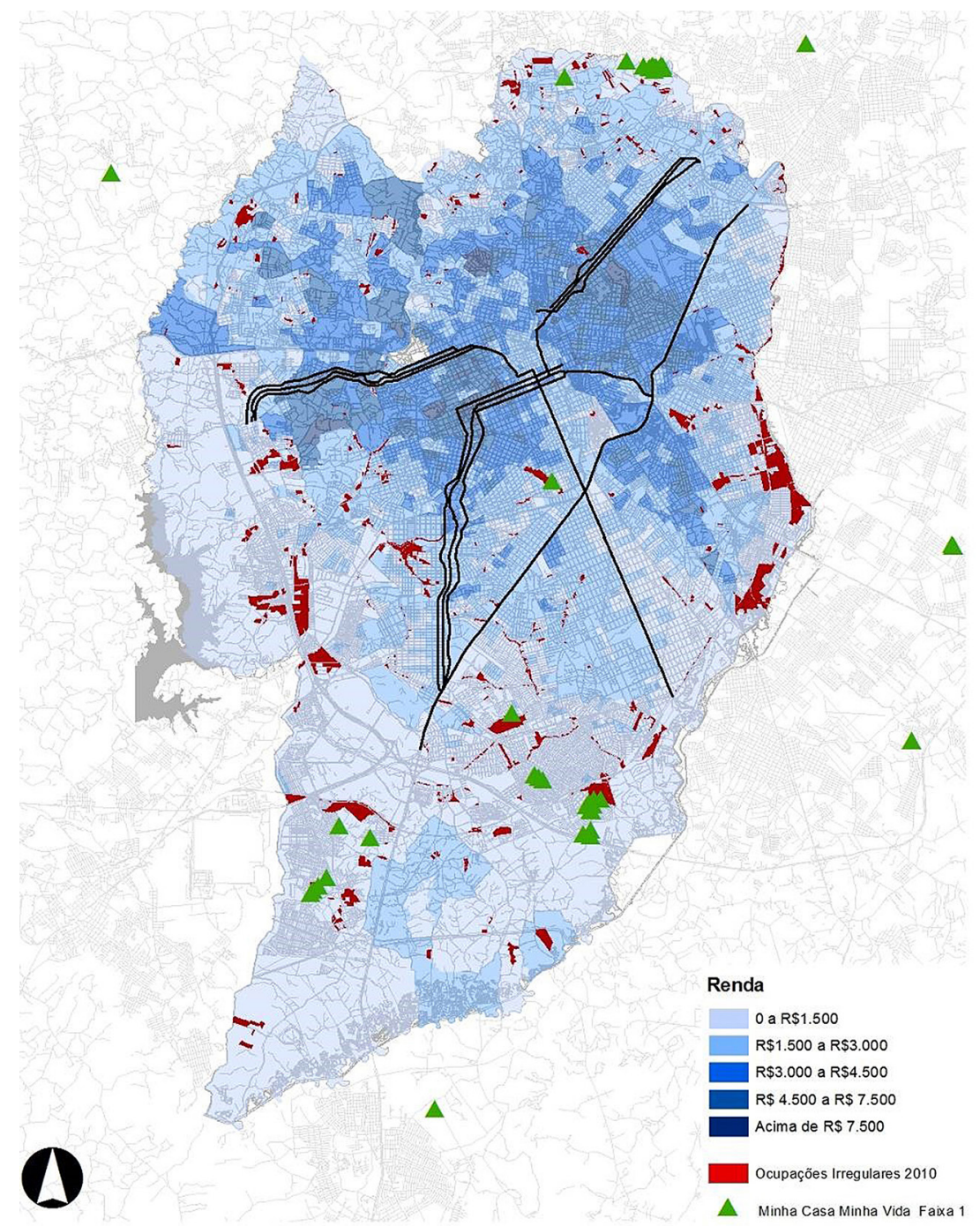

Fonte: autor, com base em dados do Ippuc e do Ministério das Cidades.

aos municípios metropolitanos, destaca-se a produção em São José dos Pinhais (18\%) e Fazenda Rio Grande $(17,1 \%)$, apesar de os maiores déficits habitacionais relativos encontrarem-se em Colombo e Almirante Tamandaré (9\%), nos quais a contratação foi pouco significativa (e mesmo inexistente, no segundo município) no segmento relativo à faixa 1. 
Tabela 2 - Unidades habitacionais contratadas pelo PMCMV na AMC (2009-2018)

\begin{tabular}{l|r|r|r|r|r|r|r|r}
\hline \multirow{2}{*}{ Município } & \multicolumn{2}{|c|}{ Faixa 1 } & \multicolumn{2}{c|}{ Faixa 2 } & \multicolumn{2}{c|}{ Faixa 3 } & \multicolumn{2}{c}{ Total } \\
\cline { 2 - 8 } & UH & \% & UH & \% & UH & \% & UH & $\%$ \\
\hline Almirante Tamandaré & 0 & 0,0 & 1.976 & 2,4 & 268 & 1,5 & 2.244 & 2,0 \\
Araucária & 0 & 0,0 & 6.877 & 8,4 & 2.107 & 11,5 & 8.984 & 8,0 \\
Campina Grande do Sul & 0 & 0,0 & 2.159 & 2,6 & 259 & 1,4 & 2.418 & 2,1 \\
Campo Largo & 447 & 4,9 & 7.059 & 8,6 & 698 & 3,8 & 8.204 & 7,3 \\
Campo Magro & 74 & 0,8 & 1 & 0,0 & 0 & 0,0 & 75 & 0,1 \\
Colombo & 253 & 2,8 & 6.740 & 8,2 & 1.316 & 7,2 & 8.309 & 7,4 \\
Curitiba & 6.073 & 66,8 & 19.379 & 23,7 & 8.282 & 45,4 & 33.734 & 30,0 \\
Fazenda Rio Grande & 509 & 5,6 & 17.269 & 21,1 & 1.530 & 8,4 & 19.308 & 17,1 \\
Itaperuçu & 0 & 0,0 & 29 & 0,0 & 5 & 0,0 & 34 & 0,0 \\
Pinhais & 0 & 0,0 & 2.522 & 3,1 & 1.069 & 5,9 & 3.591 & 3,2 \\
Piraquara & 341 & 3,8 & 4.136 & 5,0 & 416 & 2,3 & 4.893 & 4,3 \\
Quatro Barras & 7 & 0,1 & 390 & 0,5 & 78 & 0,4 & 475 & 0,4 \\
Rio Branco do Sul & 7 & 0,1 & 15 & 0,0 & 2 & 0,0 & 24 & 0,0 \\
São José dos Pinhais & 1.380 & 15,2 & 13.351 & 16,3 & 5.560 & 30,5 & 20.291 & 18,0 \\
\hline Total & 9.091 & $(8,3 \%)$ & 81.903 & $(75 \%)$ & 18.258 & $(16,7 \%)$ & & 112.584 \\
\hline
\end{tabular}

Fonte: autor, com base em dados fornecidos pelo Ministério das Cidades (2018).

A análise da produção da Cohab-CT para o período revela a manutenção da tendência de concentração da atuação do órgão apenas em Curitiba. Essa tendência também se manifesta ao se observar a evolução histórica da participação dos municípios metropolitanos na produção do órgão (Figura 5). Considerando que as 501 unidades contabilizadas em Fazenda Rio Grande no último período o foram apenas pela doação do terreno e pela prestação de apoio técnico, chega-se à quase totalidade das unidades produzidas apenas no polo.

Em relação à produção do órgão estadual de habitação, os dados disponibilizados pelo órgão (Cohapar, 2014) permitiram apenas identificar o total compilado para toda a RMC, sem a discriminação da produção por município. Apesar dessa limitação, o dado ainda possui relevância para a discussão do panorama atual da política habitacional na AMC.

Os dados obtidos indicam um total de 23.274 unidades beneficiadas entre 2011 e 2014, com predominância de processos de regularização fundiária e titulação, que juntos representam aproximadamente $63 \%$ do total do período. Conforme relato do Entrevistado 2 , os recursos para regularização fundiária estão diretamente relacionados à disponibilização de recursos do PAC, sobretudo entre 2007 e 2009. Com base nesses recursos, os projetos foram contratados, e os processos encontram-se em desenvolvimento. 
Figura 5 - Distribuição da produção da Cohab-CT entre 1967 e 2013

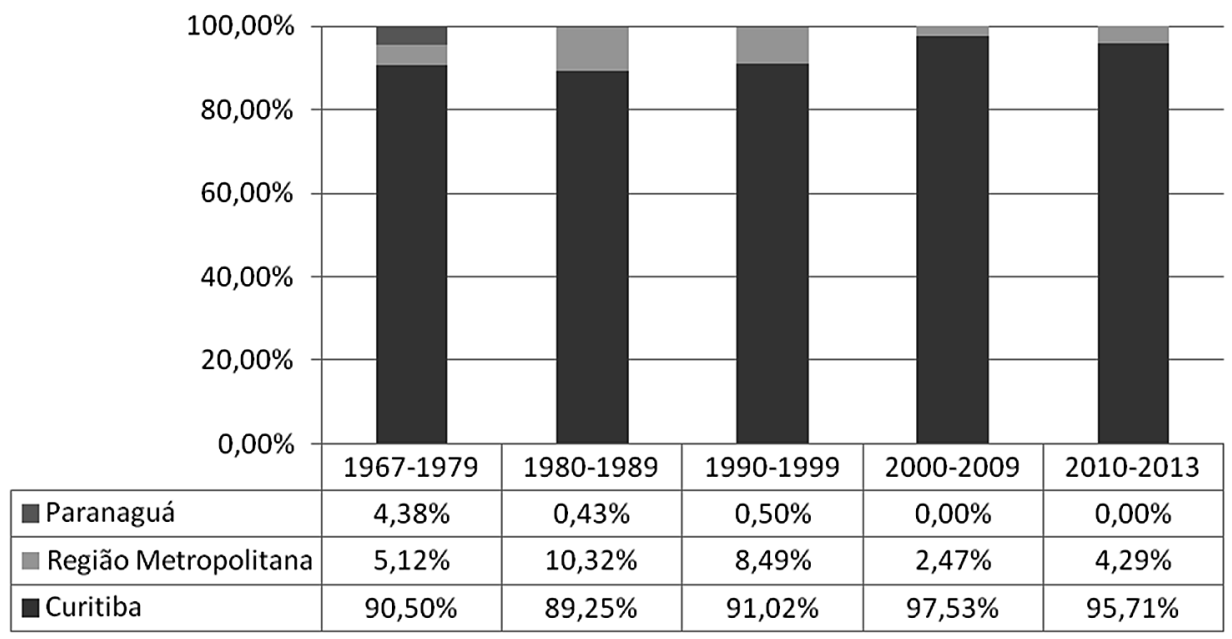

Fonte: autor, com base em dados de Cohab-CT.

A partir do lançamento do PMCMV, a atuação da Cohapar tem se concentrado na produção habitacional, tendo em vista a preponderância de recursos federais para esse fim. Nesse contexto, a realização do empreendimento em parceria com a Cohapar oferece, ao município, assessoria técnica, complementação do subsídio federal para as famílias beneficiárias e redução dos custos na implantação das infraestruturas de energia elétrica e saneamento.

Por fim, é relevante observar os valores contratados no âmbito do PAC Urbanização de Assentamentos Precários (PAC-UAP), totalizando aproximadamente $\mathrm{R} \$ 390$ milhões, investidos em oito dos quatorze municípios da AMC. A compilação dos dados disponibilizados pelo governo federal releva um quadro instigante, com distribuição equânime entre o município- polo e o município de Piraquara (Tabela 3), apesar de o município-polo concentrar, sozinho, cerca de $60 \%$ de todos os domicílios em assentamentos precários do recorte de estudo (Tabela 4).

Particularmente em relação aos assentamentos precários, não há um banco de dados que permita a compilação das informações municipais. Diante dessa limitação, a construção do panorama geral da AMC foi feita a partir da conjunção dos dados disponíveis nos PLHIS e nos estudos de Ipardes (2010) e Silva (2012). ${ }^{11}$ 
Tabela 3 - Volume de recursos investidos na AMC no âmbito do PAC-UAP

\begin{tabular}{l|c|c}
\hline \multicolumn{1}{c|}{ Município } & R\$ & $\%$ \\
\hline Almirante Tamandaré & $2.949 .632,66$ & $0,8 \%$ \\
Araucária & $9.538 .435,50$ & $2,4 \%$ \\
Campina Grande do Sul & - & $0,0 \%$ \\
Campo Largo & - & $0,0 \%$ \\
Campo Magro & $27.277 .841,60$ & $7,0 \%$ \\
Colombo & $38.475 .605,81$ & $9,9 \%$ \\
Curitiba & $145.115 .754,11$ & $37,2 \%$ \\
Fazenda Rio Grande & - & $0,0 \%$ \\
Itaperuçu & - & $0,0 \%$ \\
Pinhais & $43.990 .181,22$ & $11,3 \%$ \\
Piraquara & $113.147 .865,09$ & $29,0 \%$ \\
Quatro Barras & - & $0,0 \%$ \\
Rio Branco do Sul & - & $0,0 \%$ \\
São José dos Pinhais & $9.681 .430,58$ & $2,5 \%$ \\
\hline Total & $390.176 .746,57$ & \\
\hline
\end{tabular}

Fonte: autor, com base em dados de Brasil (2019).

Conforme pode ser observado na Tabela 4, Curitiba concentra o maior número de unidades em assentamentos precários (59,39\%), seguida de Piraquara (13,4\%), São José dos Pinhais (5,51\%), Pinhais $(3,41 \%)$ e Campo Largo (3,46\%). Deve-se também ressaltar os municípios com maior percentual de unidades em assentamentos precários em relação ao total de domicílios, critério pelo qual Piraquara $(53,70 \%)$ se destaca de todos os demais, seguido de Campina Grande do Sul (21,15\%) e Quatro Barras (11,53\%).

Atualmente, a organização espacial do aglomerado metropolitano apresenta uma inflexão em relação à histórica distribuição entre áreas centrais, ocupadas pela população de alta renda, e periféricas, ocupadas pela população de baixa renda.

Ainda que a regra seja a periferização da pobreza, ${ }^{12}$ ela se dá em áreas heterogêneas, convivendo com empreendimentos de alto padrão, notadamente condomínios horizontais. Essa alteração na configuração é resultado de um novo padrão de ocupação do território metropolitano, composto de dois vetores complementares: (1) um primeiro de reconcentração e (2) o segundo de desconcentração extensiva (Moura, Firkowski, 2014; Silva, 2012; Moura, Delgado, Cintra, 2014). 


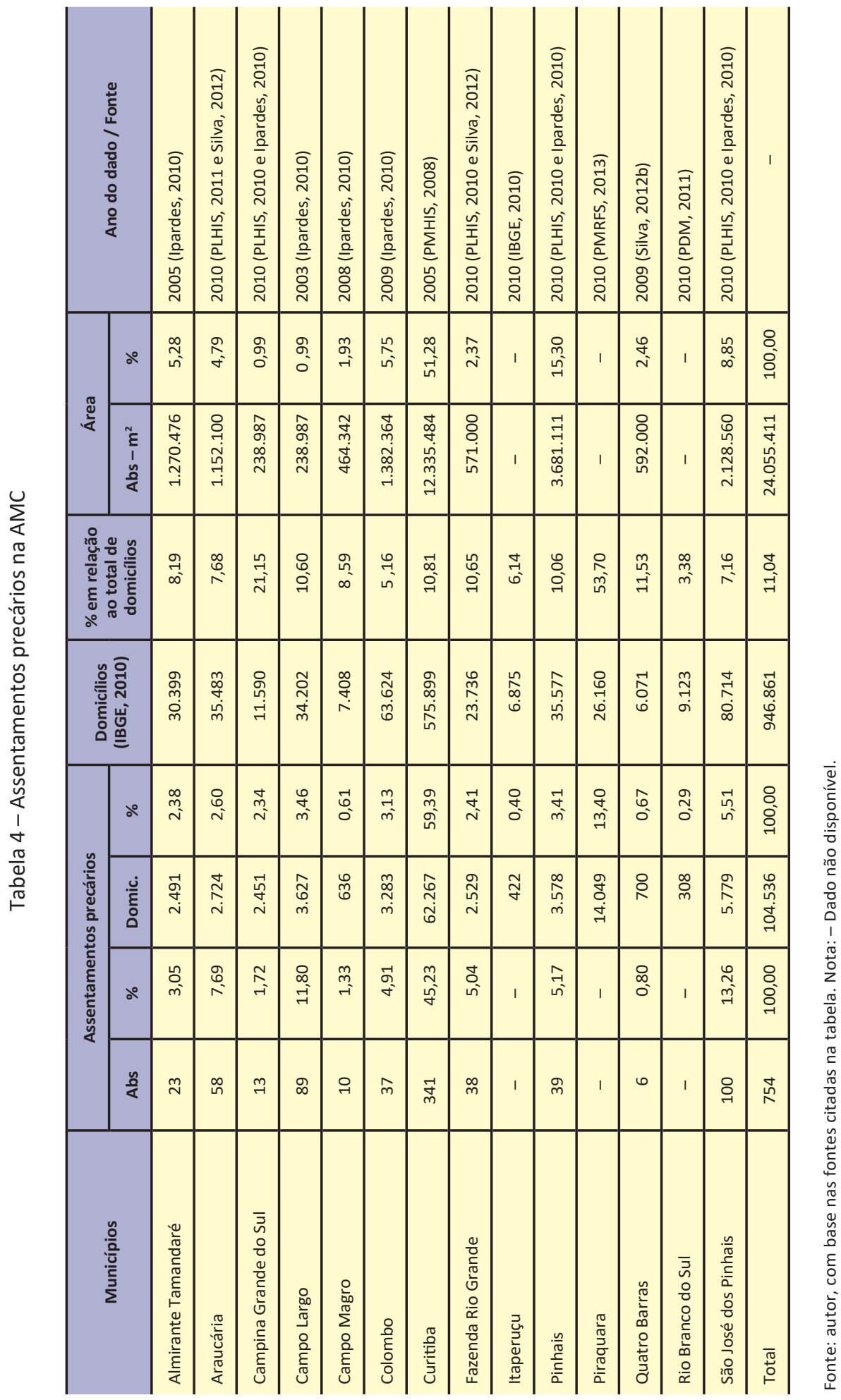


O primeiro padrão refere-se ao adensamento da mancha de ocupação contínua e, por conseguinte, dos assentamentos informais existentes em Curitiba e no entorno. Silva (2012) constata essa tendência a partir da identificação do aumento da densidade nos espaços informais de moradia consolidados, bem como pela produção de novos assentamentos próximos dos espaços preexistentes.

$\mathrm{O}$ segundo vetor, relacionado à desconcentração extensiva, tem por força motriz a produção de novas áreas residenciais, promovendo a dispersão espacial da mancha urbana, tendo por consequência a expansão dos espaços informais sobre o território dos municípios metropolitanos. A partir desse movimento ocorre a produção de novos loteamentos clandestinos na zona rural de municípios metropolitanos e a consolidação de favelas a partir de loteamentos clandestinos existentes. Nesse contexto, setores de alta renda estabeleceram-se próximos a assentamentos precários consolidados.

A despeito da mudança, a desigualdade social ainda se mantém, refletindo um modelo de ocupação urbana que induz à periferização da pobreza (Silva, 2012; Moura, Firkowski, 2014). Corroborando o exposto, a análise do órgão metropolitano, há mais de uma década, já apontava para o início dessa tendência, na qual "Almirante Tamandaré e Colombo, ao norte, assim como Pinhais a leste, e Fazenda Rio Grande ao sul, são basicamente cidades-dormitório, funcionando como bairros populares de Curitiba" (Comec, 2006, p. 59).

Por fim, deve-se fazer menção ao recente processo de desmonte da estrutura de política urbana e habitacional levado a cabo ao longo do ano de 2019, que, tendo como marco simbólico, a extinção do Ministério das
Cidades, expressa o redirecionamento de prioridades e programas do governo federal ante os dilemas urbanos. Esse movimento gera reflexos sobre o contexto local, implicando o arrefecimento dos projetos habitacionais de interesse social e a indefinição dos novos rumos das políticas subnacionais em curso.

\section{A dimensão metropolitana: discussões sobre o caso concreto}

Até este momento se buscou reconstruir a trajetória histórica da política habitacional e de gestão metropolitana na AMC, procurando caracterizá-la, a fim de encontrar sua essência nas duas últimas décadas. Ao se chegar ao panorama atual, diversos elementos explicitam a dimensão metropolitana da questão habitacional.

Essa dimensão é percebida e vivenciada de formas diversas pelos diferentes atores que interagem nas múltiplas escalas de ação e gestão existentes no espaço metropolitano. Em síntese, podem-se distinguir leituras diferenciadas a partir da escala (1) regional/metropolitana (macro); (2) [inter]municipal (meso) e (3) local (micro).

Na sequência, procura-se explicitar algumas das múltiplas facetas segundo as quais a discussão metropolitana da política habitacional pode ser interpretada na AMC. O cartograma dos casos discutidos a seguir é apresentado abaixo.

A primeira - e mais explícita - dimensão (macro) refere-se a interdependência socioespacial e econômica existente entre os municípios da área metropolitana, mais facilmente percebida a partir de uma leitura 
Figura 6 - Identificação dos casos discutidos

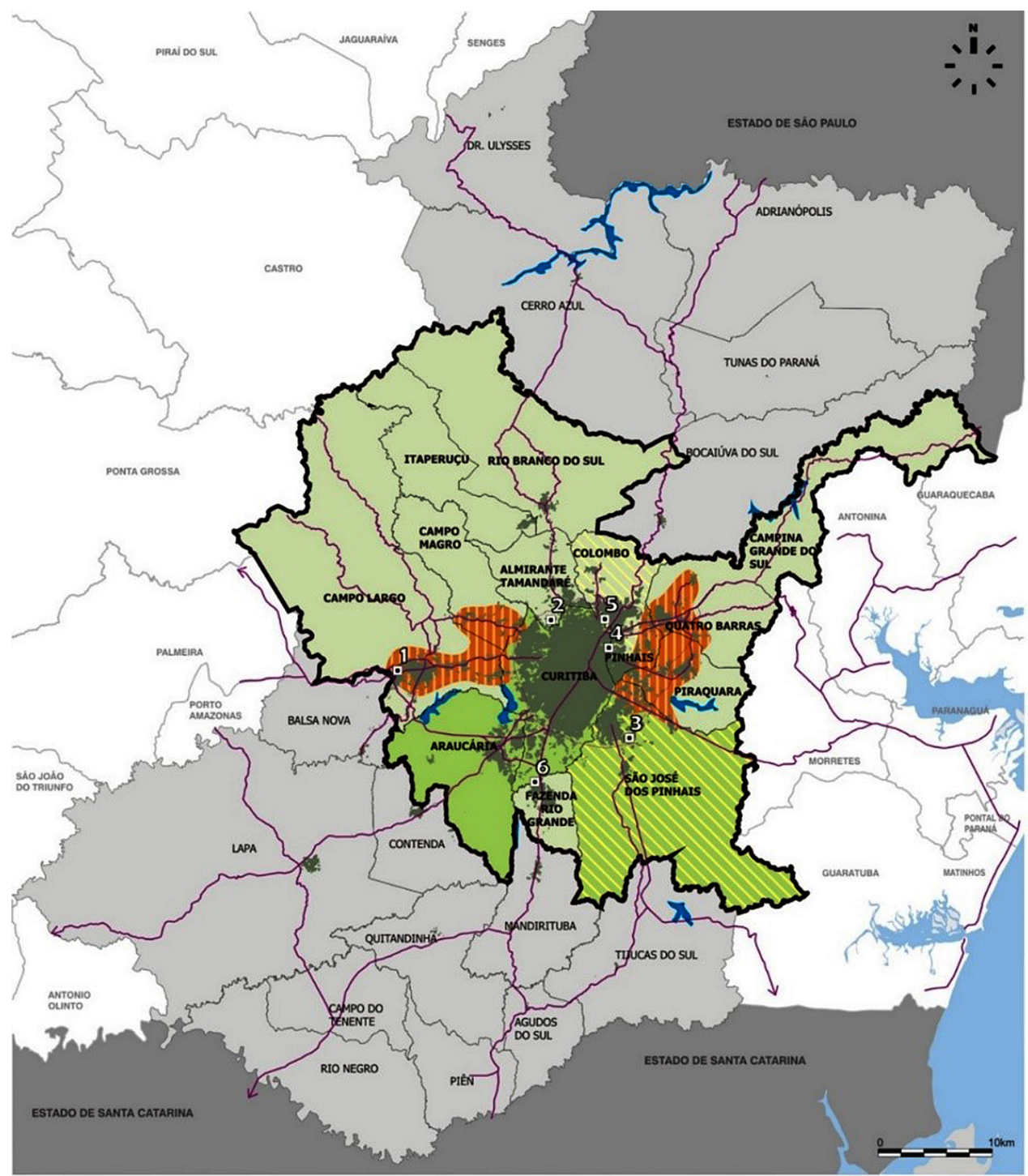

Maiores receptores

de fluxos pendulares

\section{Maiores receptores}

de fluxos migratórios

Principais conflitos entre proteção de mananciais $x$ ocupação urbana

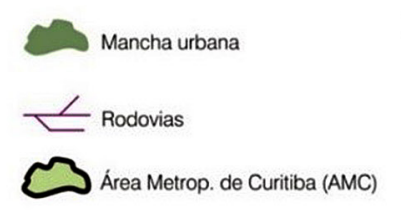

- Exemplos citados:

1. Vila Tripa (Campo Largo)

2. Ilha (Almirante Tamandaré)

3. Vila Costeira (S. José dos Pinhais)

4. Regularização fundiária $x$ ocupação da

margem oposta (Curitiba - Pinhais)

5. Área de Colombo com relação direta

com Curitiba

6. Reintegraçăo de posse em F. Rio Grande que resultou em nova ocupação irregular em Curitiba

Fonte: autor 
supramunicipal. Nesse tema, as reflexões passam, inevitavelmente, pela questão dos movimentos migratórios e pendulares. Dados compilados por Moura e Firkowski (2014) revelam que São José dos Pinhais, Pinhais e Colombo aparecem como grandes receptores de fluxos oriundos dos demais municípios metropolitanos. Em relação aos movimentos pendulares, estudo de Moura, Delgado e Cintra (2014) também coloca em destaque esses municípios, evidenciando a intensificação dos fluxos em direção ao polo. A condição de atração, antes exclusiva do polo, também passou a ser dividida com outros núcleos de concentração, com destaque para São José dos Pinhais e Araucária.

Outro aspecto relevante na escala regional refere-se à série de externalidades decorrentes do processo de metropolização, dos quais se destaca a periferização da pobreza em direção aos municípios lindeiros. Devido à limitada capacidade de gestão nesses municípios, verifica-se o espraiamento dos assentamentos precários, avançando sobre áreas de vulnerabilidade social e ambiental. Nesse contexto, o conflito mais evidente encontra-se entre a proteção das áreas de mananciais e os assentamentos informais que se consolidaram nesses espaços. Corroborando a discussão, o Plano Estadual de Habitação (2012) e o Plano de Desenvolvimento Integrado (2006) são taxativos ao afirmar que, no aglomerado metropolitano, o principal conflito se dá entre expansão urbana e preservação dos recursos hídricos.

A precariedade no controle do parcelamento do solo na década de 1970 levou à aprovação de diversos loteamentos sem a sua devida implantação na região metropolitana. Nas décadas seguintes, a delimitação dos mananciais impôs restrições ao uso e à ocupação do solo destas áreas, levando os proprietários a abandoná-las. Na esteira desse processo, a regulação do uso do solo em Curitiba e as dificuldades da população de baixa renda em acessar o mercado imobiliário formal no polo levaram um contingente significativo a ocupar essas áreas. Nesse caso, como é possível circunscrever a discussão habitacional apenas a políticas municipais desconexas?

Não se trata de conflitos fundiários promovidos apenas por dinâmicas que extrapolam os limites municipais, mas por funções públicas de interesse comum (FPIC). Apesar de o Estatuto da Metrópole ter delegado, aos estados, a definição dos campos considerados como FPICs, se partirmos somente daquelas elencadas na LCF 14/1973, são identificados diversos temas nos quais a política habitacional está diretamente imbricada: planejamento integrado do desenvolvimento social e econômico; uso do solo metropolitano; transporte e sistema viário; aproveitamento dos recursos hídricos e controle da poluição ambiental.

Em última instância, trata-se da discussão do planejamento integrado do espaço metropolitano, da gestão adequada das áreas de proteção ambiental e da provisão das infraestruturas e de serviços públicos necessários para dar suporte à dinâmica social e econômica que ocorre sobre o meio natural. Destarte, advoga-se aqui que há uma dicotomia quando a definição de um sistema de gestão dos mananciais de abastecimento de água não é acompanhada da implementação de mecanismos vinculados de planejamento e de gestão territorial, que possibilitariam a articulação das políticas urbanas. Mesmo se limitarmos a discussão aos parâmetros de uso e de ocupação do solo, é possível identificar grande incompatibilidade entre os municípios. 
Ao se aproximar da escala [inter]municipal (meso), as entrevistas realizadas ratificam as constatações realizadas. Se considerarmos os municípios significativamente atingidos pelas áreas de manancial - tais como Piraquara, Pinhais e Campo Largo -, observa-se que a visão dos gestores públicos se relaciona diretamente ao impasse entre a legislação ambiental e a ocupação existente nesses espaços. Dentro desse conflito, é recorrente a menção à necessidade de um órgão supramunicipal para promover a articulação entre os municípios para discussão integrada do problema habitacional decorrente.

Aqui é assim: 93\% do território é área de manancial e $7 \%$ é área de mata atlântica. $O$ desafio, na verdade, é que, como é área de manancial, são poucas as áreas disponíveis para conjuntos habitacionais. Não tem, a gente não consegue. As áreas que tinham já foram todas ocupadas. [...] Então, o que sobra é esse miolo, que é bem irrigado, então você vai ter muito problema com APP. Você não tem saída... (Entrevistado 15) Isso é uma questão importante [as áreas de manancial], pois Campo Largo tem três grandes áreas de APA - Rio Verde, Cambuí e Passaúna. Isso nos traz uma grande dificuldade para encontrar terrenos: ele precisa estar na área urbana, com preço acessivel, sem restrições ambientais e próximo da maIha urbana. Com isso ficamos com as mãos amarradas. (Entrevistado 9)

[...] a nossa própria dificuldade da questão manancial. Se eu não posso expandir o meu interesse social para cima dessas áreas, porque sobre essas áreas tem um segundo interesse social que não é nem menos nem mais importante, tão importante quanto, que é a preservação da água para atender uma coletividade, como eu faço com essa população que precisa morar? [...]. Então, se eu não conseguir atendê-la, eu posso contar com um município que tenha mais espaço para atendê-la? Isso nunca é conversado. (Entrevistado 14)

Um caso ilustrativo dessa discussão se refere aos assentamentos precários situados à margem dos rios que constituem divisa entre dois municípios. Como exemplo, pode-se citar aqueles situados junto ao rio Atuba, na divisa entre Curitiba e Pinhais. Ao se trabalhar com a regularização fundiária, incluem-se, nas ações, a relocação das famílias de área de risco, a melhoria das condições socioeconômicas e a recuperação ambiental das áreas degradadas, garantindo moradia digna a essa população. Nesse sentido, o trabalho de forma municipalizada é suficiente?

Ações desconexas dos dois municípios levaram à expansão alternada das ocupações na margem oposta, ${ }^{13}$ tal como relatado nas entrevistas.

No PAC então, isso ficou mais evidente porque a gente trabalhou exatamente a divisa com Curitiba. Muitas das famílias instaladas nessa área eram do Bairro Alto. Elas vieram de Curitiba. E o que a gente reparou quando da relocação? Muitas das famílias que nós relocamos e que acabaram tendo famílias excedentes naquela busca de ter mais de uma unidade, acabaram voltando para o Bairro Alto. Aquele vínculo estava muito forte. (Entrevistado 14)

O caso da comunidade "Ilha" é simbólico dessa dinâmica. A área, situada na divisa entre os municípios de Curitiba e Almirante Tamandaré, por diversos anos foi olvidada pelo poder público devido à falta de clareza sobre a qual 
municipalidade pertencia (a dúvida decorria da retificação do curso do rio Barigui). Recentemente se chegou à conclusão de que a área se situa sobre o território de Almirante Tamandaré, ${ }^{14}$ mesmo assim, as pessoas que residem na comunidade utilizam predominantemente serviços e equipamentos públicos de Curitiba (Bertol, Hoshino, 2014). Conflitos de competência semelhantes também são verificados entre Curitiba e Colombo.

O município [de Colombo] cuida exclusivamente sozinho da política habitacional. Em áreas de divisa a gente tem problemas, como no rio Atuba, divisa entre Colombo e Curitiba. Ele foi retificado e, depois disso, gera uma série de dúvidas sobre o que é Colombo e o que é Curitiba. Então tem uma conversa, mas só para resolver de quem é o problema, de quem é a competência do problema. É uma pequena área, que na verdade é de Colombo. Mas a relação dela é toda com Curitiba, tanto é que é até Curitiba que faz a coleta de lixo de lá. (Entrevistado 10)

Para Bertol e Hoshino (ibid.), o contexto atual de acirramento dos conflitos fundiários urbanos nos espaços metropolitanos não tem sido acompanhado do proporcional incremento de atenção por parte das instâncias de planejamento territorial. Para os autores, compreender a natureza desses dilemas a partir da perspectiva dos atores locais contribui para maior clareza das múltiplas facetas dessa questão.

A esquizofrenia do território, nessa conjuntura, se expressa no fato de que, embora o cidadão se constitua, na prática, como cidadão de um lugar, e embora, para os que estão ali alojados, o lugar desprezado pelos demais seja um espaço de vida, o território, quando deixa a invisibilidade no planejamento, quando ganha luminosidade nos mapas do Estado, passa a ser convocado como suporte para interesses e vetores externos ao lugar vivido. (p. 475)

Nesse contexto, a dimensão metropolitana para a política habitacional é vivenciada pela população local a partir do binômio coerção-omissão, limitando-se a estabelecer condições e restrições, relegando a resolução das demandas habitacionais à escala local. Pode-se citar, como exemplos desta dimensão vivenciada (micro), os casos da vila Nova Costeira (São José dos Pinhais) e da vila Tripa (Campo Largo).

O primeiro caso se enquadra na leitura da dimensão metropolitana como elemento alheio à realidade local. A vila Nova Costeira é um assentamento informal de cerca de 300 famílias, cuja origem remonta a um processo de relocação realizado na década de 1990 pela prefeitura municipal em parceria com a Comec sobre área da própria prefeitura, lindeira ao aeroporto Afonso Pena. A regularização do parcelamento nunca foi concluída, "resultando em uma situação perene de insegurança jurídica da posse para a comunidade" (ibid., p. 455) e em desacordo aos parâmetros locais de densidade, uso e ocupação do solo.

Em 2011, um decreto estadual declarou a área e alguns loteamentos vizinhos como de utilidade pública para fins de desapropriação, com vistas à expansão do aeroporto. Em síntese, um projeto metropolitano implicaria a remoção de uma comunidade que até o momento não recebera atenção do poder público. Como a área ainda permanece como loteamento irregular, a única opção ofertada pela prefeitura municipal foi o cadastramento das famílias, para sua transferência para futuros 
empreendimentos do PMCMV realizados no município. Nas palavras dos autores,

[...] após vinte anos de omissão e invisibilidade do Estado, objeto dos súbitos holofotes da imprensa, dos políticos e dos planejadores em prol de uma intervenção que requer o espaço de radicação da comunidade para propósitos totalmente alheios às suas demandas [...]. (Ibid., p. 471)

Da prévia invisibilidade para o poder público, em nível tanto municipal quanto metropolitano, a comunidade passou abruptamente à posição de destaque, como elemento indesejado no território. Situação semelhante é constatada no caso da vila Tripa, comunidade com mais de 20 anos e cerca de 75 famílias, situada em Campo Largo às margens da PR423 - entre as duas pistas da BR-277. Sua condição de invisibilidade ao planejamento formal transformou-se a partir das obras do contorno rodoviário da BR-277. Conforme bem sintetizado pelo Entrevistado 9,

Com as obras para o Contorno de Campo Largo (duplicação BR-277), houve uma série de implicações para essas pessoas. A passagem das máquinas para a movimentação de terra da obra destruiu a ligação de água irregular que alimentava a comunidade. Os gatos de energia elétrica foram cortados. Também foram fechados os acessos para lá. Se você for lá hoje, não vai nem conseguir entrar, pois a concessionária colocou uma mureta, que impede o acesso de veículos para a comunidade. Com isso, os moradores da vila Tripa que possuíam carro não conseguem nem acessar suas casas, somente a pé.
A dimensão metropolitana, diante dos elementos discutidos, mostra-se notadamente presente na imposição de limitações legais e regulação do parcelamento do solo, mas é notadamente ausente na criação de formas de articulação entre os municípios e na promoção de instrumentos e mecanismos de planejamento integrado para a política habitacional. Em última instância, a ausência de um processo de planejamento metropolitano e articulação dos diferentes atores sociais e territoriais favorece os interesses da produção corporativa do espaço e, por conseguinte, contribui para "tornar mais desigual o espaço metropolitano, aprofundando a exclusão social (Moura, Firkowski, 2014, p. 39).

\section{Considerações finais}

No Brasil, os debates envolvendo a articulação de políticas públicas no território metropolitano têm retomado sua pujança na última década, vinculando-se, mais recentemente, aos debates envolvendo o Estatuto das Metrópoles. Esse processo estimulou uma série de estudos sobre os obstáculos e entraves à plena consecução de políticas de corte metropolitano, que, em algumas políticas setoriais, como mobilidade e resíduos sólidos, foram acompanhadas de avanços no setor público. A política habitacional, contudo, ainda permanece alheia aos debates e pesquisas em desenvolvimento, demandando a ampliação de discussões e estudos dirigidos, com vistas ao fomento do redesenho de políticas públicas que propiciem a articulação interfederativa. 
Análises mais gerais da performance de políticas habitacionais geralmente se concentram em números absolutos de produção de unidades e processos de regularização fundiária. Dentro dessa concepção, pensar a integração das políticas municipais de habitação pode parecer menos importante. A depender da formação e das preferências do leitor, este pode julgar o tema da articulação regional de menor importância quando comparado à discussão sobre a dinâmica produtiva, a qualidade da moradia ou o processo de financeirização da política. Contudo, discutir estratégias de viabilização de uma política metropolitana de habitação constitui ação fundamental, sem a qual se arrisca a perpetuar o ciclo de reprodução socioespacial da pobreza e a utilização da política habitacional como instrumento de produção de unidades precárias e mal localizadas, vedetes de pleitos eleitorais de qualquer candidato em qualquer nível governamental.

Ainda, não se pode olvidar o descompasso existente entre os limites jurisdicionais e a distribuição territorial da demanda metropolitana (que não respeita esses limites), conjuntura que implica maior instabilidade e insuficiência nas políticas públicas engendradas, agravadas ao se considerar o apelo político de um tema como a política habitacional.

Inserido nessa discussão, este artigo buscou avançar no delineamento da concretude da dimensão metropolitana da demanda habitacional, deslocando a discussão de possibilidades para aquela das necessidades. Os resultados obtidos permitem identificar um palimpsesto de demandas, dinâmicas e interesses, que se colidem no espaço metropolitano. É fundamental trazê-los à luz, expor suas características, de forma a evitar distorções na consecução das políticas públicas, tendo por objetivo a garantia da função social da propriedade e do direito à cidade que, conforme lembram Hoshino e Moura (2019), se inserem na escala metropolitana no cenário urbano contemporâneo. Essa escala, como bem pontuou Klink (2013, p. 85), é "permanentemente construída, desarticulada e recriada pelos agentes sociais em função dos seus projetos políticos".

Se adotarmos a clássica definição de política pública como "o que o governo escolhe fazer ou não fazer" (Dye, 2011), torna-se possível especular sobre o insuficiente interesse na resolução do problema habitacional em termos mais amplos (metropolitano), bem como sobre o excesso de interesse na captação e produção de unidades habitacionais isoladamente pelos municípios (local), resultando em falsas soluções de rápida efetivação que respondem, essencialmente, a necessidade de geração de capital político.

Outro aspecto relevante a ser ressaltado se refere à configuração da Área Metropolitana de Curitiba como caso tipificante da realidade dos espaços metropolitanos no Brasil. A análise da trajetória histórica das políticas de habitação e gestão metropolitana demonstra que o caso da metrópole de Curitiba possui as contradições clássicas da urbanização excludente que marcou a evolução urbana brasileira ao longo das últimas décadas. Essa constatação permite, ainda que com ressalvas, extrapolar as conclusões obtidas para outros espaços metropolitanos.

Por fim, é necessário salientar que a pesquisa empírica realizada apresenta restrições decorrentes de sua natureza interpretativista, ou seja, ela está fortemente vinculada à avaliação do pesquisador, sua percepção do fenômeno estudado e, ainda que forma tangencial, à sua visão de mundo. 
Complementarmente, por se utilizar de entrevistas, o estudo esteve sujeito ao ponto de vista dos respondentes, cujo posicionamento político e ideológico, especialmente dos gestores públicos participantes, pode influenciar em suas respostas. Todavia, entende-se que limitações de pesquisa são características intrínsecas à sua própria natureza e estão diretamente relacionadas ao desenvolvimento de trabalhos futuros.

\section{[l] http://orcid.org/0000-0002-8518-9978}

Pontifícia Universidade Católica do Paraná, Escola de Arquitetura e Design, Programa de Pós-Graduação em Gestão Urbana. Curitiba, PR/Brasil. paulo.neto@pucpr.br

\section{Notas}

(1) Conforme identificado por diversas fontes (Firkowski, 2013; Balbim et al., 2011; Ipea, 2013; IBGE, 2008), apesar da profusão de regiões metropolitanas institucionalizadas no Brasil, grande parte delas não guarda aderência ao fato metropolitano. Nesse contexto, a RM de Curitiba integra o conjunto das doze RMs na qual as referidas fontes reconhecem a efetiva presença do fato metropolitano.

(2) A denominação, que o órgão metropolitano passa a adotar a partir do Plano de Desenvolvimento Integrado de 2003, engloba atualmente os municípios de Almirante Tamandaré, Araucária, Campina Grande do Sul, Campo Largo, Campo Magro, Colombo, Curitiba, Fazenda Rio Grande, Itaperuçu, Pinhais, Piraquara, Quatro Barras, Rio Branco do Sul e São José dos Pinhais.

(3) Com exceção de Curitiba, os demais municípios do recorte de estudo concentram as funções de planejamento e execução da política habitacional em um único órgão.

(4) É importante ressaltar que os resultados expressam a visão pessoal dos entrevistados, não tendo sido solicitada a visão institucional do órgão. Para contrapor ao posicionamento oficial, foram analisadas as disposições expressas no Plano Diretor Municipal e no Plano Setorial de Habitação, discutidos em maiores detalhes na sequência.

(5) Neste trabalho, parte-se do conceito de triangulação de dados defendido por Stake (2005). Para o autor, observações e interpretações não são plenamente reproduzíveis, de forma que a triangulação pode não somente ratificar informações de múltiplas fontes, como também explicitar diferentes pontos de vista sobre a mesma questão. Assim, as divergências entre os dados coletados em cada fonte não reduzem a validade da pesquisa, mas evidenciam contradições inerentes ao fenômeno pesquisado. Nesse contexto, não se buscou a simples identificação de relações de causa e efeito, mas o significado fornecido pelos participantes. 
(6) Para Schussel (2006), a aprovação do Estatuto das Cidades (lei n. 10.257/2001) foi decisiva para a mudança de abordagem no processo de elaboração do PDI, visto que ele enfatiza a participação popular nas decisões referentes ao futuro das cidades.

(7) A delimitação dessas zeis foi motivada por demanda do Ministério das Cidades, de forma a garantir a obtenção de recurso federal proveniente do PAC.

(8) Uma discussão ampliada dessa questão pode ser encontrada em recente artigo publicado pelo autor (Polucha, Nascimento Neto, 2019).

(9) É necessário ressaltar que esse levantamento não contemplou os municípios de Piraquara e Colombo, historicamente marcados pela existência de assentamentos precários. Segundo a própria autora, "Piraquara, em especial, tem um peso importante na concentração de assentamentos com grandes superfícies no leste do aglomerado metropolitano, [...] que em meados da década de 2000 tinha mais de 43.000 residentes" (Silva, 2012, p. 198).

(10) Cabe ressaltar que o referido decreto foi concebido em decorrência do lançamento do PMCMV, flexibilizando parâmetros para a viabilização de empreendimentos vinculados ao programa.

(11) Essa tabela resulta do esforço de construir um quadro geral do panorama atual das ocupações irregulares na AMC. Ainda que não haja uma normalização estatística da quantificação, a reunião desses dados possui relevância para a macrocompreensão no recorte territorial de estudo.

(12) Os empreendimentos imobiliários verticais do tipo "superior" continuam possuindo vinculação direta com a organização do território metropolitano, e a periferia continua abrigando a parcela da população mais pobre e de menor escolarização (Bertol, Hosinho, 2014; Moura, Firkowski, 2014).

(13) "Outro exemplo de fenômenos dessa natureza foi a reintegração de posse de uma área ocupada por uma comunidade há mais de 10 anos no município de Fazenda Rio Grande próximo à divisa com Curitiba; ação que levou as famílias a ocupar irregularmente uma área de risco situada na porção extremo sul de Curitiba" (Entrevistado 18).

(14) Um aspecto interessante é que o gestor municipal envolvido com a política habitacional em Almirante Tamandaré, ao ser questionado, informou que não existem ocupações irregulares próximas às divisas do município (Entrevistado 8).

\section{Referências}

ARRETCHE, M. et al. (2012). Capacidades administrativas dos municípios brasileiros para a política habitacional. Brasília/São Paulo, Ministério das Cidades/CEM.

BALBIM, R. N.; BECKER, M. F.; COSTA, M. A. e MATTEO, M. (2011). Desafios contemporâneos na gestão das regiões metropolitanas. Revista Paranaense de Desenvolvimento. Curitiba, n. 120, pp. 149-176.

BARDIN, I. (1994). Análise de conteúdo. Lisboa, Edições Setenta.

BERTOL, L. E.; HOSHINO, T. de Z. P. (2014). “A Ilha e a Costeira: a (in)visibilidade dos conflitos fundiários no planejamento territorial da Região Metropolitana de Curitiba”. In: FIRKOWSKI, O. L.; MOURA, R. (eds.). Curitiba: transformações na ordem urbana. Rio de Janeiro, Letra Capital. 
BONDUKI, N. (2013). "Planos locais de habitação: das origens aos dilemas atuais nas Regiões Metropolitanas". In: DENALDI, R. Planejamento habitacional - Notas sobre a precariedade e terra nos planos locais de habitação. São Paulo, Annablume.

BRASIL (2019). Dados sobre projetos no âmbito do PAC-UAP. Disponível em: www.pac.gov.br/ infraestrutura-social-e-urbana/urbanizacao-de-assentamentos-precarios/pr/. Acesso em: ago 2018.

CARDOSO, A. L. (org.). (2013). O programa Minha Casa Minha Vida e seus efeitos territoriais. Rio de Janeiro, Letra Capital.

CARDOSO, A. L.; ARAGÃO, T. A.; ARAUJO, F. de S. (2011). Habitação de interesse social: política ou mercado? Reflexos sobre a construção do espaço metropolitano. In: XIV ENCONTRO NACIONAL DA ANPUR. Anais... Rio de Janeiro, Anpur.

CARDOSO, A. L.; ARAGÃO, T. A.; JAENISCH, S. T. (2017). 22 anos de política habitacional no Brasil: da euforia à crise. Rio de Janeiro, Letra Capital.

COHAB-CT (2006). COHAB-CT: 41 anos de planejamento e realizações. Boletim Casa Romário Martins, v. 30, n. 133.

COHAPAR (2012). Plano Estadual de Habitação de Interesse Social do Paraná. Paraná, Governo do Estado.

(2015). Cronograma de obras do PAC. Disponível em: <http://www.cohapar.pr.gov.br/modules/ conteudo/conteudo.php?conteudo=112>. Acesso em: jan 2015.

COMEC (2006). Plano de Desenvolvimento Integrado da Região Metropolitana de Curitiba: propostas de ordenamento territorial e novo arranjo institucional. Curitiba, Comec.

COSTA, G. M. et al. (2010). Planos diretores e políticas territoriais: reflexões a partir de transformações no Vetor Norte da RMBH. Revista Paranaense de Desenvolvimento, n. 119, pp. 79-106.

COSTA, H. S. de M.; MENDONÇA, J. G. de (2010). Urbanização recente e disputa pelo espaço na dinâmica imobiliária metropolitana em Belo Horizonte. In: XVII ENCONTRO NACIONAL DE ESTUDOS POPULACIONAIS. Anais... Caxambu, Minas Gerais.

DENALDI, R.; KLINK, J.; SOUZA, C. (2010). "Habitação, inclusão social e governança urbana colaborativa”. In: CASTRO, E.; WOJCIECHOWSKI, M. J. (orgs.). Inclusão, colaboração e governança urbana: perspectivas brasileiras. Rio de Janeiro, Observatório das Metrópoles.

FIRKOWSKI, O. L. C. F. (2013). “Metrópoles e regiões metropolitanas no Brasil: conciliação ou divórcio?”. In: FURTADO, B. A.; KRAUSE, C. e FRANÇA, K. C. B. de (eds.). Território metropolitano, políticas municipais: por soluções conjuntas de problemas urbanos no âmbito metropolitano. Brasília, Ipea.

FIX, M.; PEREIRA, A. L. dos S. (2013). "Metrópole brasileira nas políticas públicas setoriais". In: FURTADO, B. A.; KRAUSE, C.; FRANÇA, K. C. B. de (eds.). Território metropolitano, políticas municipais. Brasília, Ipea.

FJP - Fundação João Pinheiro (2000). Déficit habitacional no Brasil. Belo Horizonte, FJP. (2010). Déficit habitacional municipal no Brasil. Belo Horizonte, FJP. (2013). Déficit habitacional municipal no Brasil. Belo Horizonte, FJP.

GLASER, B.; STRAUSS, A. (2006). The discoverey of grounded theory: strategies for qualitative research. Londres, AldineTransaction. 
GODOI, A. S. (2006). “Estudo de Caso Qualitativo”. In: GODOI, C.; BANDEIRA-DE-MELLO, R.; SILVA, A. Pesquisa qualitativa em estudos organizacionais. São Paulo, Saraiva.

GONÇALVES, R. da R. (2011). Política habitacional na federação brasileira: o lugar dos governos Estaduais. In: XIV ENCONTRO NACIONAL DA ANPUR. Anais... Rio de Janeiro.

GORSDORF, L. F. (2009). “A dimensão metropolitana nos planos diretores municipais da Região Metropolitana de Curitiba”. In: MOURA, R. e FIRKOWSKI, O. L. (orgs.). Dinâmicasintrametropolitanas e produção do espaço na Região Metropolitana de Curitiba. Curitiba, Letra Capital.

HOSHINO, T. de A. P.; MOURA, R. (2019). Politizando as escalas urbanas: jurisdição, território e governança no Estatuto da Metrópole. Cadernos Metrópole. São Paulo, v. 21, n. 45, pp. 371-392.

IBGE - INSTITUTO BRASILEIRO DE GEOGRAFIA E ESTATÍSTICA (2008). Rede de Influência das cidades. Rio de Janeiro, IBGE.

(2010a). Aglomerados subnormais - Censo Demográfico 2010. Rio de Janeiro, IBGE.

(2010b). Censo demográfico 2010. Rio de Janeiro, IBGE.

INPESPAR (2019). Análise da oferta de imóveis usados à venda em Curitiba. Disponível em: http:// www.inpespar.com.br. Acesso em: ago 2019.

IPARDES - Instituto Paranaense de Desenvolvimento Econômico e Social (2010). Assentamentos precários urbanos: espaços da Região Metropolitana de Curitiba: relatório II. Curitiba, Ipardes.

IPEA - Instituto De Pesquisa Econômica Aplicada (2013). 40 anos de regiões metropolitanas no Brasil. Brasília, Ipea.

KLINK, J. (2013). "Por que as regiões metropolitanas continuam tão ingovernáveis?". In: FURTADO, B.; KRAUSE, C.; FRANÇA, K. (orgs.). Território metropolitano, políticas municipais: por soluções conjuntas de problemas urbanos no âmbito metropolitano. Brasília, Ipea.

KORNIN, T.; CARMO, J. C. B. do (2013). “O arranjo institucional de gestão na Região Metropolitana de Curitiba”. In: COSTA, M. A.; TSUKUMO, I. T. L. (orgs.). 40 anos de regiões metropolitanas no Brasil. Brasília, Ipea.

LEITÃO, S. R. (2010). Inclusão do excluído? Política de mobilidade e dinâmica do mercado de terras Na expansão da Curitiba metrópole. Tese de Doutorado. São Paulo, Universidade de São Paulo.

MARGUTI, B. O.; COSTA, M. A.; FAVARÃO, C. B. (orgs.) (2018). Brasil metropolitano em foco: desafios à implementação do Estatuto da Metrópole. Brasília, Ipea.

MARICATO, E. (2011). Metrópoles desgovernadas. Estudos Avançados, v. 25, n. 71, pp. 7-22.

(2014). O impasse da política urbana no Brasil. Petrópolis, Vozes.

MCIDADES - MINISTÉRIO DAS CIDADES (2009). Plano Nacional de Habitação. Brasília, Ministério das Cidades.

MINISTÉRIO DAS CIDADES (2018). Produção pelo Programa Minha Casa Minha vida segundo município. Relatório técnico. Brasil, Ministério das Cidades.

MOURA, R.; DELGADO, P. R.; CINTRA, A. P. de U. (2014). "A metrópole de Curitiba na rede urbana brasileira e sua configuração interna". In: FIRKOWSKI, O. L.; MOURA, R. (eds.). Curitiba: transformações na ordem urbana. Rio de Janeiro, Letra Capital. 
MOURA, R.; FIRKOWSKI, O. L. (2014). "Transformações na ordem urbana da RMC". In: FIRKOWSKI, O. L.; MOURA, R. (ed.). Curitiba: transformações na ordem urbana. Rio de Janeiro, Letra Capital.

NASCIMENTO NETO, P.; MOREIRA, T. A. (2014). Novas equações para antigas incógnitas: a questão habitacional no Brasil sob a ótica da produção acadêmica nacional. Revista Brasileira de Pós-graduação (Capes), n. 24.

(2017). The Metropolitan Dimension of Housing Policy. Mercator, v. 16, pp. 1-13.

POLUCHA, R.; NASCIMENTO NETO, P. (2019). ZEIS X SEHIS: Análise crítica a partir do caso de Curitiba, PR. In: XVIII ENCONTRO NACIONAL DA ANPUR. Anais... Natal, Anpur.

RIBEIRO, L. C. de Q. (2004). “A Metrópole: entre a coesão e a fragmentação, a cooperação e o conflito”. In: RIBEIRO, L. C. de Q. (org.). Metrópoles: entre a coesão e a fragmentação, a cooperação e o conflito. Rio de Janeiro, Fase.

(org.) (2009). Hierarquização e identificação dos espaços urbanos. Rio de Janeiro, Letra Capital/ Observatório das Metrópoles.

ROLNIK, R.; SOMEKH, N. (2004). “Governar as metrópoles: dilemas da recentralização”. In: RIBEIRO, L. C. de Q. (org.). Metrópoles: entre a coesão e a fragmentação, a cooperação e o conflito. Rio de Janeiro, Fase.

ROYER, L. de O. (2009). Financeirização da política habitacional: limites e perspectivas. Tese de Doutorado. São Paulo, Universidade de São Paulo.

ROYER, L. de O. (2013). “Municípios 'autárquicos' e região metropolitana: a questão habitacional e os limites administrativos". In: FURTADO, B. A.; KRAUSE, C.; FRANÇA, K. C. B. de (eds.). Território metropolitano, políticas municipais: por soluções conjuntas de problemas urbanos no âmbito metropolitano. Brasília, Ipea.

SANTOS JR., O. (coord.) (2009). Arranjos Institucionais para a Gestão Metropolitana. Relatório de Pesquisa - Território, coesão social e governança democrática. Rio de Janeiro, CNPq.

SCHUSSEL, Z. das G. L. (2006). A aglomeraçăo metropolitana de Curitiba e as tendências contemporâneas do planejamento urbano. Tese de Doutorado. Curitiba, Universidade Federal do Paraná.

SHIMBO, L. Z. (2012). Habitação social, habitação de mercado: a confluência entre estado, empresas construtoras e capital financeiro. Belo Horizonte, C/Arte.

SILVA, M. N. da (2012). A dinâmica de produção dos espaços informais de moradia e o processo de metropolização em Curitiba. Tese de Doutorado. Curitiba, Universidade Federal do Paraná.

SOUZA, B. C. M. F. de (2009). Desenvolvimento regional e gestão metropolitana: reflexões a partir da política habitacional na região metropolitana de Aracaju. Dissertação de Mestrado. Sergipe, Universidade Federal do Sergipe.

STAKE, R. (2005). "Case Studies". In: DENZIN, N.; LINCOLN, T. Handbook of qualitative research. Londres, Sage.

YIN, R. K. (2005). Case Study Research. Londres, Bookman. 